\title{
Análisis de montos y tasas del mercado de simultáneas en Colombia*
}

\author{
Amount Analysis and market rates \\ of simultaneous in Colombia
}

\author{
Valeria Roberto-Vargas ${ }^{*}$ \\ Kimberly Rojas-Silva**
}

* $\quad$ Este documento fue publicado en el Reporte de Mercados Financieros del Banco de la República del 1T19. Se agradece especialmente la asesoría de Juan Sebastián Rojas Moreno y de Lina Vanessa Patiño Echeverri en la estructuración y el desarrollo de esta investigación.

Las opiniones expresadas en este documento son responsabilidad de los autores y no comprometen al Banco de la República ni a su Junta Directiva. Cualquier error u omisión en el contenido de este documento es responsabilidad exclusiva de los autores.

** Profesional en Finanzas y Comercio Internacional. Profesional del Departamento de Operaciones y Desarrollo de Mercados del Banco de la República, Bogotá, Colombia [vroberva@ banrep.gov.co].

*** Magíster en finanzas. Profesional Especializado del Departamento de Operaciones y Desarrollo de Mercados del Banco de la República, Bogotá, Colombia [krojassi@banrep. gov.co].

Artículo recibido el 15 de marzo de 2019.

Aceptado el 10 de mayo de 2019.

Para citar este artículo:

Roberto Vargas, V. y Rojas Silva, K. (2019). Análisis de montos y tasas del mercado de simultáneas en Colombia. ODEON, 17, pp. 107-156.

DOI: https://doi.org/10.18601/17941113.n17.05 


\section{Resumen}

El objetivo de este documento es identificar si el mercado de simultáneas, además de reflejar las condiciones de liquidez en pesos, ofrece información sobre las expectativas de desvalorizaciones de los bonos soberanos. Para ello, se clasifica cada operación (el estudio incluye las operaciones de simultáneas pactadas a plazo de un día hábil en el Sistema Electrónico de Negociación del Banco de la República, entre octubre de 2008 y abril de 2018) en tres rangos, que se construyen a partir del promedio y la desviación estándar del margen -entre la tasa promedio ponderada por monto de las simultáneas negociadas a plazo overnight y la tasa de política monetaria-. Los resultados muestran que la mayoría de operaciones se concentran en el rango medio, cuyo margen se ubica entre \pm una desviación estándar. El análisis descriptivo y estadístico de cada rango permite concluir que altos volúmenes de operaciones de simultáneas pactadas a tasas inusualmente bajas podrían indicar expectativas de desvalorizaciones de los bonos locales.

Palabras clave: simultáneas; mercado monetario; estrategias en corto; TES. Clasificación JEL: D84, E41, G1.

\section{Abstract}

The main goal of this paper is to identify if the market of secured liquidity operations called "simultáneas" reflects the devaluation expectations in the sovereign Colombian bond market, besides the liquidity conditions of the money market. In order to achieve it, each operation (Traded in the Electronic Trading System between October 2008 and April 2018) is classified in three ranges, built using the media and standard deviation of the spread - between the weighted average rate of the liquidity market operations and the monetary policy rate. The results show that most of the operations are concentrated in the medium range, with a spread between \pm one standard deviation. The descriptive and statistical analysis of each range allows to conclude that high volumes of "simultáneas" traded at unusual low rates might reflect the devaluation expectations in the local bond market.

\section{Key words:}

JEL classification: D84, E41, G1. 


\section{Introducción}

En el presente artículo se realiza una caracterización del funcionamiento del mercado de simultáneas a partir del análisis de la evolución del margen entre la tasa promedio ponderada por monto de las simultáneas a plazo overnight (Tsim) y la tasa de política monetaria (TPM) ${ }^{1}$. Este análisis se lleva a cabo para extraer información relacionada con: i) las condiciones de liquidez del mercado, y ii) las expectativas de desvalorizaciones de los títulos de deuda pública (TES) ${ }^{2}$ en el mercado de contado.

El documento se compone de cinco secciones. La primera sección presenta las generalidades del mercado de simultáneas y los hechos estilizados relacionados con el margen. La segunda sección se enfoca en algunos episodios de interés en los que se detectaron operaciones de simultáneas a tasas atípicas por un tiempo sostenido, y describe los principales eventos tanto a nivel internacional como local a los que podría asociarse dicho comportamiento. La tercera sección presenta el análisis de las simultáneas por cada tipo de título usado como colateral en estas operaciones, tanto TES en pesos como en unidades de valor real (UVR). La cuarta sección muestra los resultados del análisis econométrico de los datos. En la quinta sección se presenta un análisis de escenarios con montos representativos a tasas bajas. Por último, se esbozan algunas conclusiones.

\section{Caracterización del mercado de simultáneas}

Una operación simultánea es aquella en la que el Agente 1 (posición activa) entrega una suma de dinero al Agente 2 (posición pasiva). Este último, entrega al Agente 1 títulos valores como colateral (transferencia de la propiedad) y se compromete a pagarle una tasa de interés sobre los recursos recibidos (tasa de la simultánea). Al vencimiento de la operación, en el mismo día o en una fecha futura, el Agente 1 devuelve los títulos valores (transferencia de la propiedad) al Agente 2, quien le paga los recursos en pesos más los intereses pactados (figura 1).

1 En adelante "margen".

2 Bonos emitidos por el Tesoro Nacional de Colombia. 
Figura 1: Operaciones simultáneas
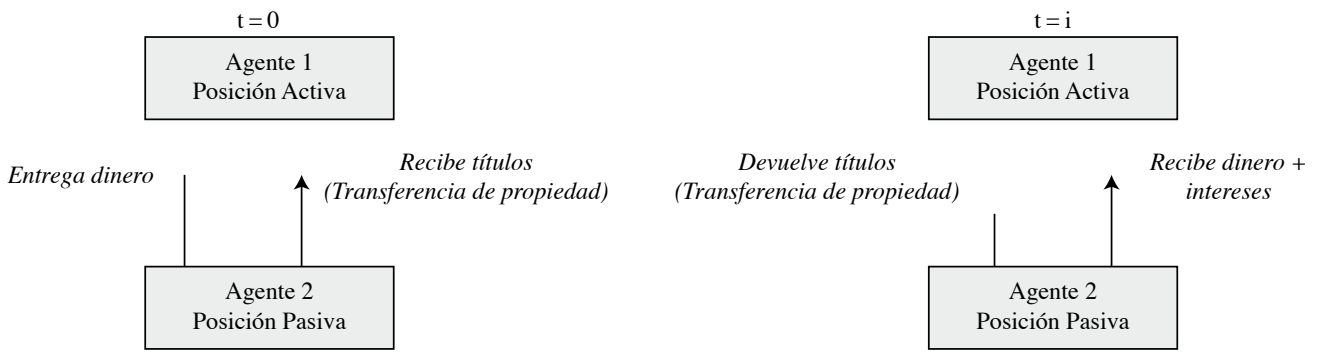

Las operaciones simultáneas se pueden negociar a través de sistemas de negociación, como el Sistema Electrónico de Negociación del Banco de la República (SEN) y Master Trader ${ }^{3}$, o en el mercado mostrador ${ }^{4}$. En este documento se analizan las simultáneas pactadas en el SEN durante el periodo comprendido entre octubre de 2008 y abril de 2018. La información analizada corresponde a la de cada operación ejecutada (tick-by-tick).

En la figura 2 se presenta con frecuencia diaria la evolución del margen total (línea negra) y su descomposición en tres rangos (R1, R2 y R3), así como los montos negociados diariamente en cada rango como porcentaje del total diario negociado. El margen total diario suele ser negativo, es decir, la Tsim generalmente es inferior a la TPM ${ }^{5}$. El promedio de este margen es de $-25,4$ p.b. y su desviación estándar es de 38,4 p.b. En el 70\% de los días analizados, el margen total diario se ubica en el rango R2, mientras que en el $28 \%$ de los días se ubica en el rango R3 y el $2 \%$ restante se sitúa en el rango R1. A continuación, se presenta una caracterización de cada uno de los rangos.

- R1 (Rango 1-serie azul): simultáneas a plazo de un día, pactadas a tasas con margen superior a una desviación estándar del margen total diario. Estas operaciones concentran en promedio el $9 \%$ del monto diario negociado y pueden reflejar restricciones de liquidez en pesos.

3 Este sistema reemplazó el 10 de septiembre de 2018 al Mercado Electrónico Colombiano (MEC) de la Bolsa de Valores de Colombia.

4 Cuando las operaciones se pactan en el mercado mostrador, se deben registrar en los sistemas de negociación. Por lo general, los agentes prefieren registrarlas en Master Trader.

5 Por esta razón, en adelante, cuando se menciona que "el margen aumentó" indica que se hizo menos negativo, es decir, que la Tsim aumentó. 
- R2 (Rango 2-serie verde): simultáneas a plazo de un día, pactadas a tasas con margen entre \pm una desviación estándar del margen total diario. Teniendo en cuenta que -en promedio- el $78 \%$ del monto diario negociado se encuentra en este rango, y que -en comparación con los otros rangos- la Tsim presenta la menor desviación frente a la TPM, este rango podría considerarse como el escenario de liquidez "normal".

Figura 2: Análisis por rangos de márgenes - periodo completo Margen: Tasa Simultáneas SEN - TPM

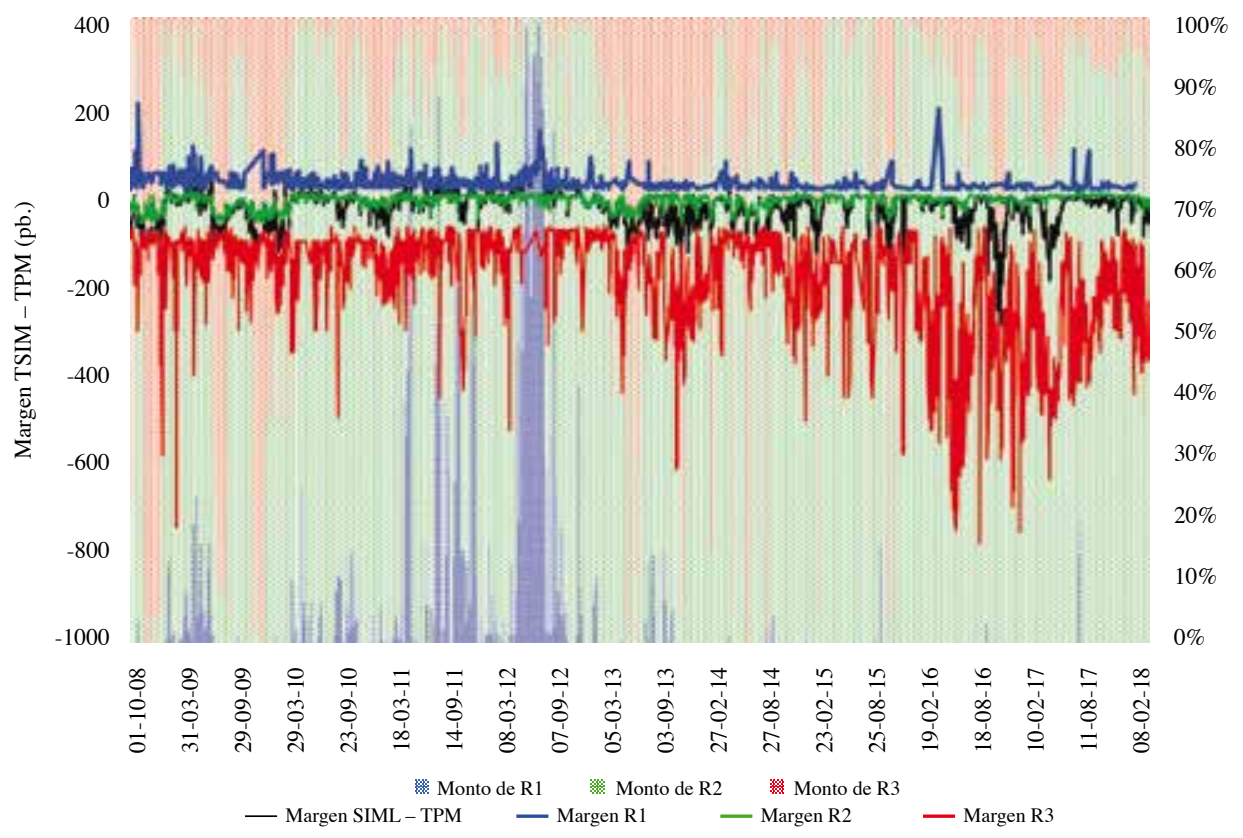

Fuente: cálculos propios; base de datos SEN.

- R3 (Rango 3-serie roja): simultáneas a plazo de un día, pactadas a tasas con margen inferior a una desviación estándar del margen total diario. En este rango se concentra en promedio el $13 \%$ del monto diario negociado. Operaciones en este rango podrían interpretarse como señales de que el mercado cuenta con un nivel holgado de liquidez en $\operatorname{pesos}^{6}$. Adicionalmente,

6 En casos de última instancia, con el objeto de evitar mantener los recursos ociosos, los agentes podrían acudir a la ventanilla de contracción del Banco de la República, que remunera los recursos a una tasa 100 p.b. por debajo de la TPM. 
las operaciones en este rango también podrían tomarse como señales de que existen incentivos para otorgar los recursos a tasas bajas a cambio de obtener temporalmente un título. Esto último se da principalmente por la necesidad de cobertura de estrategias en corto en el mercado secundario de $\mathrm{TES}^{7}$.

\section{Análisis de episodios de interés}

Históricamente, la Tsim ha presentado desviaciones de la TPM asociadas tanto a las condiciones de liquidez en el mercado monetario como a expectativas de desvalorizaciones de los TES. A continuación, se hace un análisis de los episodios en los cuales la Tsim se ha desviado de forma significativa de la TPM con el fin de establecer si dichas desviaciones respondieron a condiciones particulares de liquidez o si reflejan otros factores.

\subsection{Desviación de Tsim por encima de TPM ${ }^{8}$}

\subsubsection{Julio-Septiembre de 2012}

Este periodo estuvo caracterizado por altas necesidades de liquidez ante el aumento de los depósitos de la Tesorería de la Nación en el Banco de la República (BR) en julio9 . Estos recursos tenían como fin principal el pago de vencimientos de TES por un monto que ascendía a $\$ 7$ billones (en el periodo de análisis).

Para suplir las necesidades de liquidez, el BR aumentó los montos de la subasta de repos a 1 día desde $\$ 2,9$ billones a mediados de abril hasta máximos

$7 \quad$ Agentes del mercado sugirieron que del monto de las simultáneas un porcentaje entre 70 y $90 \%$ se pacta por búsqueda de liquidez, y que el porcentaje restante (entre 30 y $10 \%$ ) se pacta por búsqueda de títulos (Banco de la República: reunión semestral de operadores del mercado financiero, segundo semestre de 2018).

8 Pese a que algunos agentes manifestaron percibir niveles estrechos de liquidez cuando se implementó el Decreto 1068 de 2015, con el cual se incorporó a todas las entidades del orden nacional que forman parte del Presupuesto General de la Nación en el Sistema de Cuenta Única Nacional, la Tsim no estuvo presionada al alza en 2015, debido a que la participación de los depósitos de las entidades públicas en el total de los depósitos de los establecimientos de crédito era en ese entonces de $0,15 \%$, de modo que el impacto en la liquidez del mercado no fue significativo.

9 Producto de: i) el pago de dividendos de Ecopetrol cuyo mayor participante era el Estado y ii) la devolución de impuestos por montos importantes a la DGCPTN. 
históricos de $\$ 15,1$ billones en julio. Posteriormente, el BR convocó a subastas de expansión con plazos superiores a un día ${ }^{10}$, pero la utilización de estas operaciones fue baja y el costo de fondeo en el mercado se mantuvo alto debido a que gran parte de los agentes prefirieron cubrir sus necesidades de liquidez diariamente.

La baja disponibilidad de recursos también se reflejó en la disminución del monto recibido en la ventanilla de contracción a 1 día del BR desde finales de marzo de 2012. En este contexto de baja liquidez, las tasas del mercado monetario (Tsim, TIB e IBR) estuvieron presionadas al alza, y la TIB llegó a superar la TPM en un máximo histórico de 30 p.b.

\subsection{Desviación de Tsim por debajo de TPM}

\subsubsection{Marzo 2013-Abril 2014}

Este periodo estuvo caracterizado por condiciones de amplia liquidez y expectativas de desvalorizaciones de los TES en el corto plazo, como se expone a continuación:

- A inicios de 2013, surgieron especulaciones sobre una posible modificación del cálculo de la rentabilidad mínima de los Fondos de Pensiones Obligatorias y Cesantías que podría causar desvalorizaciones en algunas referencias de TES y en la deuda corporativa ${ }^{11}$.

10 El 2 de agosto, el BR convocó a subastas de repos de expansión a plazo de 7 días por un cupo de $\$ 4$ billones, que se hicieron de forma continua hasta el 24 de octubre con un cupo promedio de $\$ 2,3$ billones y un monto adjudicado promedio de $\$ 613 \mathrm{~mm}$. El 7 de noviembre, el BR reinició las subastas a 7 días y además convocó a las de 14 días; sin embargo, la demanda de recursos no fue significativa en ninguna de las dos.

11 El índice tendría cinco índices representativos: el COLCAP para la renta variable local, el COLTES para la renta fija local, el Global Aggregate Bond Index de Barclays para la renta fija internacional, el Morgan Stanley Capital International World Index para la renta variable internacional y el COLIBR para los depósitos a la vista. De esta manera, se esperaba una menor demanda de: i) TES de largo plazo debido a que el índice COLTES había presentado una duración modificada histórica de 4, que estaba por debajo de la duración de los portafolios de los Fondos de Pensiones Obligatorias, ii) TES en UVR dado que el índice COLTES solo incluía títulos con tasa fija, y iii) títulos de deuda privada dado que no había ningún índice representativo que incluyera este tipo de activos. Esta modificación al decreto se aplazó hasta el año 2014. 
- Había expectativas de aumentos de la TPM por parte del BR, y por tanto de desvalorizaciones de los TES, después de que la inflación en abril (publicada en mayo) fue superior a la esperada y que la Junta Directiva del Banco de la República (en adelante Junta Directiva) decidió en su reunión de abril aumentar el pronóstico de crecimiento de la economía.

- Las expectativas de desvalorizaciones de los TES también estuvieron relacionadas con una mayor percepción de riesgo a nivel internacional, debido a las preocupaciones en torno a la posible disminución o finalización del programa de compra de activos de la Reserva Federal antes de lo esperado. En septiembre, se disiparon las preocupaciones tras el anuncio de la Reserva Federal de mantener inalterado su programa de estímulo monetario.

- En 2013, el promedio diario del monto recibido en la ventanilla de contracción a 1 día registró el segundo valor histórico más alto con $\$ 410 \mathrm{~mm}$ (después de un episodio en 2008 cuando había sido igual a $\$ 464 \mathrm{~mm}$ ), lo que reflejaba las condiciones de amplia liquidez.

- Para reducir el exceso de liquidez, el BR realizó subastas de depósitos remunerados a plazos de 7 y 14 días, entre marzo y abril de $2013^{12}$. El monto de estas operaciones fue de $\$ 10,3$ billones ${ }^{13}$ durante el episodio analizado.

- Esta coyuntura de amplia liquidez pudo haber presionado las tasas a la baja. El margen entre la TIB y la TPM alcanzó a ser de 2 dígitos (alrededor de - 10 p.b.) entre mediados de marzo y principios de abril de 2014 , lo que no se observaba desde junio de 2013.

La Tsim aumentó a niveles más cercanos a la TPM después del anuncio del incremento de la participación de Colombia en los índices de JP Morgan (19 de marzo) ${ }^{14}$. Esta decisión contribuyó a las valorizaciones que presentaron los TES después del anuncio, y desincentivó las estrategias en corto.

12 Los últimos dos periodos en los que convocó este tipo de operación fueron febrero de 2011 y abril de 2010 .

13 Para los depósitos remunerados a plazo de 7 días el monto fue $\$ 5,9$ billones y para 14 días fue $\$ 4,4$ billones.

14 La participación aumentó en los índices GBI-EM Global Diversified y GBI-EM Global, de $3,24 \%$ a $8,05 \%$ y de $1,81 \%$ a $5,6 \%$, respectivamente.

ODEON, ISSN: 1794-1113, E-ISSN: 2346-2140, № 17, julio-diciembre de 2019, pp. 107-156 


\subsubsection{Segundo semestre de 2016}

Las tasas de las simultáneas posiblemente estuvieron influenciadas por un entorno negativo para los TES, que pudo motivar la toma de posiciones cortas en títulos de deuda pública local. La liquidez no parece haber tenido un comportamiento inusual, debido a que el BR no tuvo la necesidad de remunerar depósitos a plazos superiores a 1 día y en la subasta de repos a 1 día únicamente el $15 \%$ de los días el monto demandado fue inferior a $\$ 3$ billones. A continuación, se explica el contexto internacional de este periodo:

- En el Reino Unido y la Unión Europea, los mercados presentaron volatilidad ante el desarrollo de la campaña para el Brexit y su posterior victoria en el referendo del 23 de junio. El Banco de Inglaterra anunció medidas de estímulo ante la disminución de las perspectivas de crecimiento del Reino Unido ${ }^{15}$.

- Incertidumbre respecto a la tendencia del precio del petróleo debido a que por un lado había exceso de oferta y, por otro lado, la OPEP y Rusia gestionaban la firma de un acuerdo para reducir la producción.

- En la reunión de diciembre, la Reserva Federal aumentó su TPM en 25 p.b. por primera vez en el año y ofreció una perspectiva ligeramente más positiva de crecimiento e inflación, con pronósticos de mayores incrementos de tasa para el 2017 frente a los señalados en su reunión anterior. Esto contribuyó a la desvalorización de los bonos gubernamentales a nivel global y al fortalecimiento del dólar americano.

- Hacia finales de septiembre, eventos relacionados con las elecciones presidenciales estadounidenses generaron una mayor percepción de riesgo ${ }^{16}$. Luego de la victoria de Donald Trump, la volatilidad de los mercados aumentó ante la incertidumbre en torno a las políticas que aplicaría. Los mercados de economías emergentes se vieron afectados por el aumento de las tasas de los Treasuries, en un entorno de expectativas de mayor gasto fiscal e inflación en Estados Unidos.

15 El Banco de Inglaterra redujo su tasa a un mínimo histórico de 0,25\%. El Ministerio de Economía británico indicó que el PIB del Reino Unido disminuiría a un ritmo de $6 \%$ anual hasta el año 2018, con una desvalorización de la propiedad inmobiliaria del $18 \%$ y la pérdida de 820 mil empleos.

16 Por ejemplo, la reapertura de la investigación del FBI contra Hillary Clinton por posibles filtraciones de información clasificada. 


\section{Análisis de las simultáneas por título}

En esta sección se analizan, de forma discriminada por tipo de título TES en pesos y en UVR, los montos pactados y las desviaciones de la Tsim frente a la TPM, con el objeto de identificar si existen preferencias por referencias específicas (figura 3$)^{17}$ al pactar operaciones de simultáneas.

Figura 3: TES en PESOS y UVR: promedio anual de montos y márgenes diarios
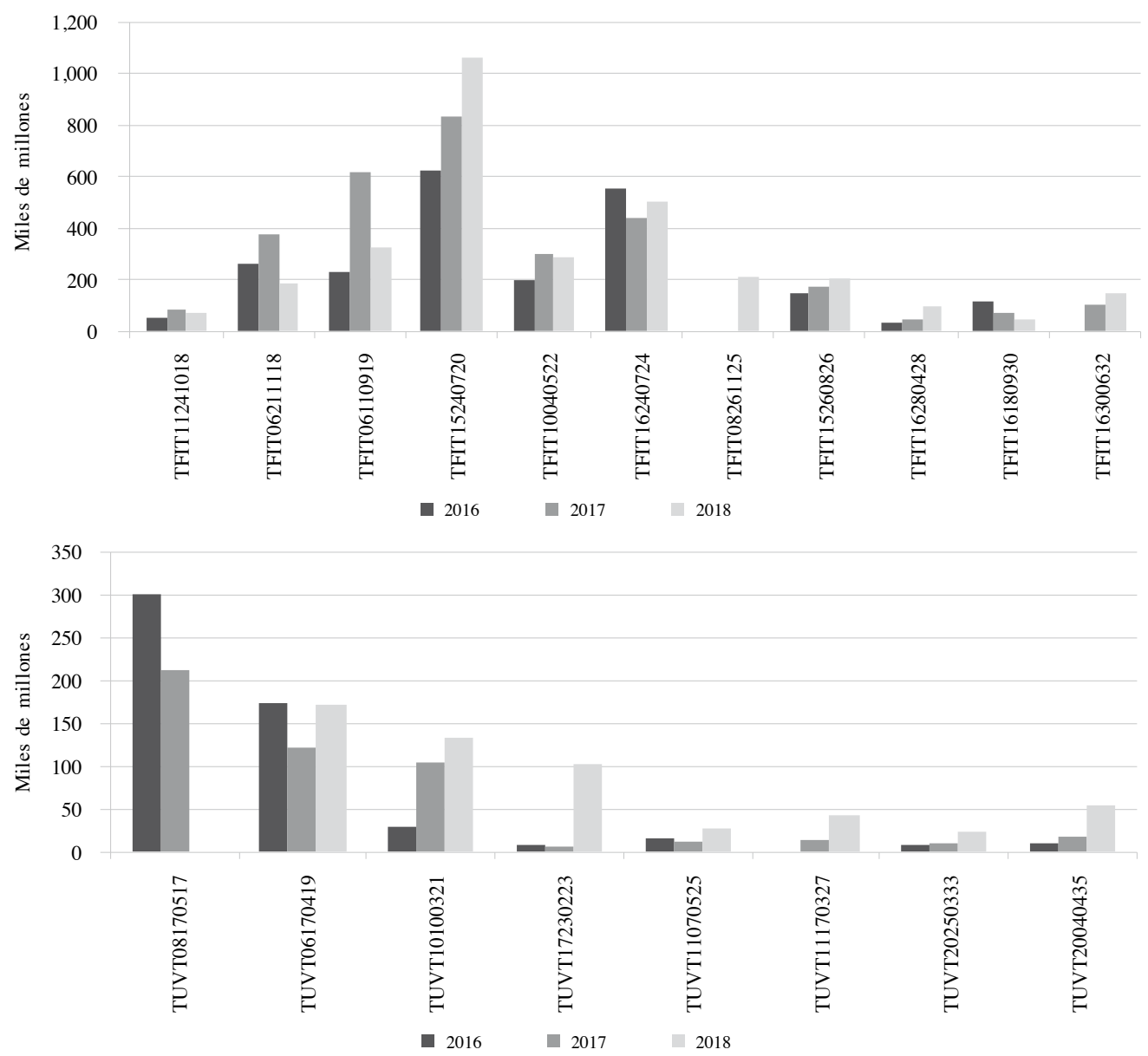

17 Para efectos prácticos, únicamente se muestran los montos y márgenes de los títulos que estaban vigentes entre enero de 2016 y abril de 2018. 


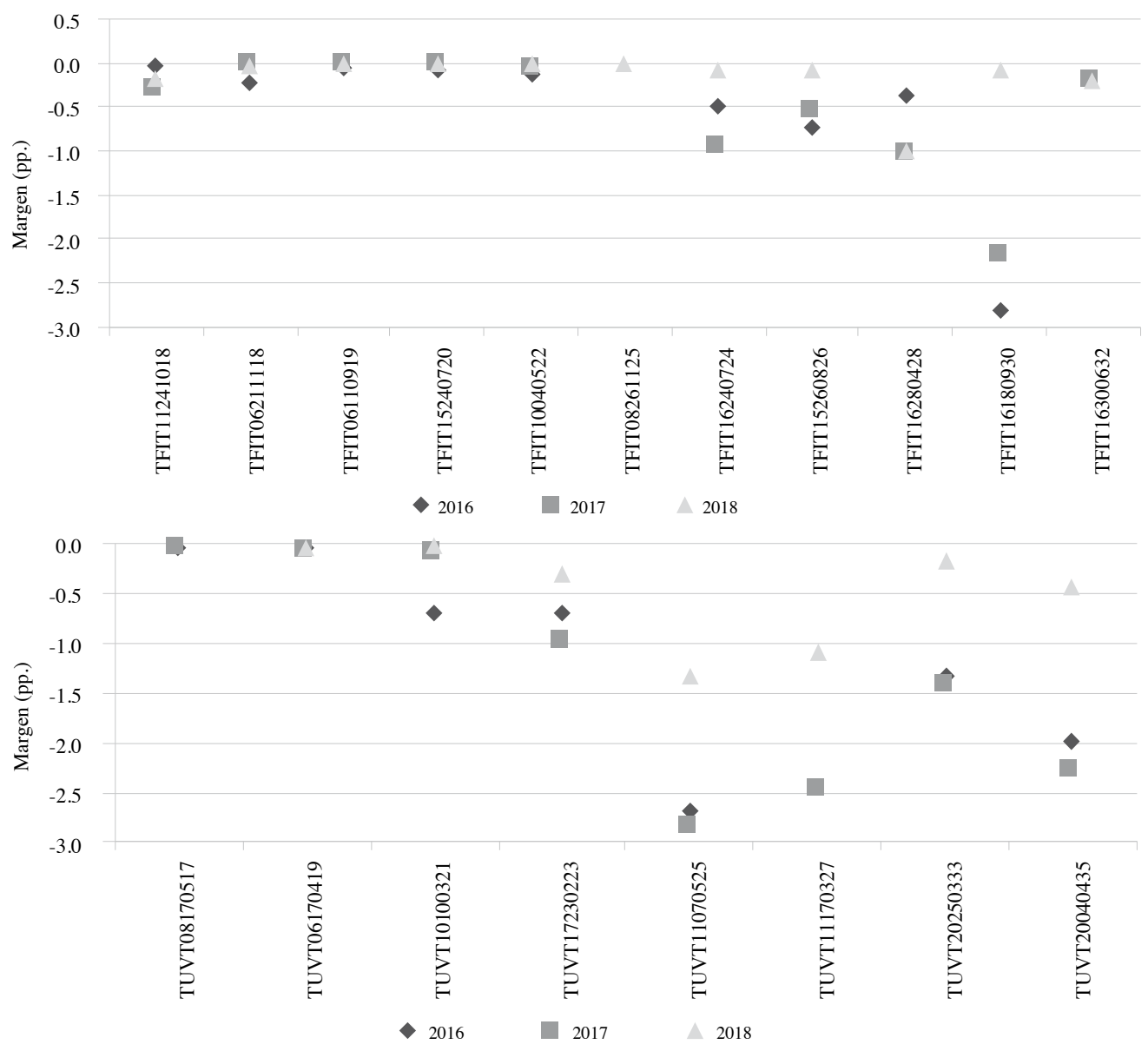

En primer lugar, se encuentra que los montos transados en simultáneas con TES en pesos son sustancialmente mayores a aquellos de simultáneas con TES denominados en UVR. Esto obedece a que los títulos en pesos tienen mayor saldo en circulación, y, por tanto, son los más utilizados para pactar operaciones de liquidez. Adicionalmente, los principales tenedores de TES en UVR son entidades que no transan activamente en el mercado debido a que tienen estrategias de inversión del tipo buy and hold -como inversionistas extranjeros, Fondos de Pensiones y Cesantías, Aseguradoras y el Banco de la República (BR), entre otros- y, por tanto, estos títulos son considerados "escasos"18.

18 La escasez también puede obedecer a que las entidades que poseen los títulos no tienen necesidades de liquidez, y, por tanto, no acuden al mercado de simultáneas. Varios agentes 
En segundo lugar, los márgenes de las operaciones con TES en pesos suelen ser menores -en términos absolutos- que los de las operaciones con TES en UVR. Además, se observa que en la medida en que el volumen de simultáneas negociado en una referencia es más pequeño, el margen es más amplio. Esto podría explicarse porque si un agente decide realizar una estrategia en corto sobre un título poco utilizado en el mercado de simultáneas, se expone a tener que pactar la operación a una tasa muy baja, con una desviación significativa frente a la TPM.

Adicionalmente, en el caso de los TES en pesos, parece existir una relación entre las desvalorizaciones del mercado secundario de los títulos y las desviaciones de la Tsim por debajo de la TPM. Esto se explica por la posible implementación de operaciones en corto de los títulos. Otros factores ${ }^{19}$, como la búsqueda de referencias específicas producto de la segmentación del mercado ${ }^{20}$ o la cobertura de operaciones NDF sobre $\mathrm{TES}^{21}$, podrían generar desviaciones en la Tsim en simultáneas pactadas con ciertos títulos, sin que necesariamente indiquen cambios en las condiciones de liquidez en pesos del sistema o cubrimiento de posiciones cortas en el mercado de TES.

coinciden en que no hay preferencia por un plazo o por un tipo de título en el momento de buscar recursos en pesos, y que se utilizan los títulos disponibles de acuerdo con la composición de su portafolio de liquidez (Banco de la República: reunión semestral de operadores del mercado financiero, segundo semestre de 2018).

19 Según agentes del mercado, cada razón que explica la búsqueda de títulos en el mercado de simultáneas (expectativas de desvalorización de los títulos, cobertura de operaciones NDF sobre TES y segmentación del mercado) es igual de probable, aunque las ponderaciones dependen de las condiciones específicas de cada entidad (Banco de la República: reunión semestral de operadores del mercado financiero, segundo semestre 2018).

20 La segmentación surge de la distinción entre agentes con y sin acceso al mercado del SEN. Si un agente ( $\sin$ acceso al SEN) vende un título que no tiene en su portafolio, tiene que conseguirlo a través de la intermediación de un operador con acceso a la plataforma. El operador con acceso al SEN estaría dispuesto a colocar sus recursos en pesos en el mercado de simultáneas a tasas bajas para conseguir el título, únicamente si obtiene ganancias producto de la intermediación, es decir, si su cliente compensa el costo de obtener el título.

21 Si un agente vendió TES a futuro y quiere disminuir su exposición al riesgo de mercado, acudirá al mercado de simultáneas para obtener el título y cubrirse de las fluctuaciones del precio en el mercado secundario, mientras se hace el cumplimiento de su operación a futuro. 


\subsection{Análisis de referencias específicas}

En esta sección se presenta el análisis por tipo de título. Para este análisis se escogieron los TES denominados en pesos que vencen en jul-20, jul-24, y sep-30, y los TES denominados en UVR que vencen en mar- 21 y abr-35. Los criterios que se usaron para la escogencia de los títulos fueron: i) altos montos transados en los rangos R2 y R $3^{22}$, ii) comportamiento atípico (mayores desviaciones hacia abajo de la TPM de la Tsim) durante el periodo de interés o durante episodios puntuales, y iii) comentarios de agentes encuestados que los identifican como títulos sobre los que es más evidente la realización de estrategias en corto en el mercado de contado de TES.

En las figuras 4 a 8, por cada título se presenta la evolución del monto negociado en simultáneas (serie azul), la tasa promedio de cada título en el mercado de simultáneas ponderada por monto (serie negra), la tasa promedio ponderada por monto de todas las simultáneas (Tsim total: serie naranja), la tasa de negociación del título en el mercado de contado (serie verde) y la TPM (serie roja).

\section{PESOS: JUL-20}

Este título es uno de los más representativos de acuerdo con el monto negociado, especialmente en el rango R2. La Tsim del título se desvía más de la TPM al inicio del periodo de análisis, cuando el título no era uno de los más líquidos en el mercado de simultáneas ni en el de TES y, por tanto, las estrategias para cubrir operaciones en corto en el mercado de contado eran más evidentes.

Los periodos en los que la Tsim del título se desvía más de la TPM son 2009, 2011, 2013 y 2014. En la figura 4 se observa que los momentos en los que la Tsim del título se aleja más de la TPM, coinciden con periodos en los que la tasa del título en el mercado secundario aumenta. Lo anterior da indicios de que las desvalorizaciones que presentaba la referencia podrían haber incentivado la toma de posiciones cortas, y a su vez la negociación de simultáneas a tasas bajas.

A partir de 2015, los montos transados en las simultáneas con este título aumentan y es menos común que la Tsim del título sea significativamente baja

22 Los títulos que más volumen en pesos concentran en las simultáneas pactadas a tasas inusualmente bajas (rango R3) fueron: TES en pesos con vencimiento en jul-24 de julio, jun-16 de junio, nov-18, sep-30 y jul -20, y TES en UVR con vencimiento en mar-21, may-25, may-17 o, abr-19 y abr-35. 
respecto a la TPM, incluso cuando la desviación de la Tsim total es importante, como es el caso de los episodios de 2016 y de 2017. En el último año del periodo de análisis ${ }^{23}$, este título concentra el $26 \%$ del monto total negociado en el mercado de simultáneas y es considerado como uno de los más líquidos tanto en el mercado de simultáneas como en el de TES.

Figura 4: TFIT15240720

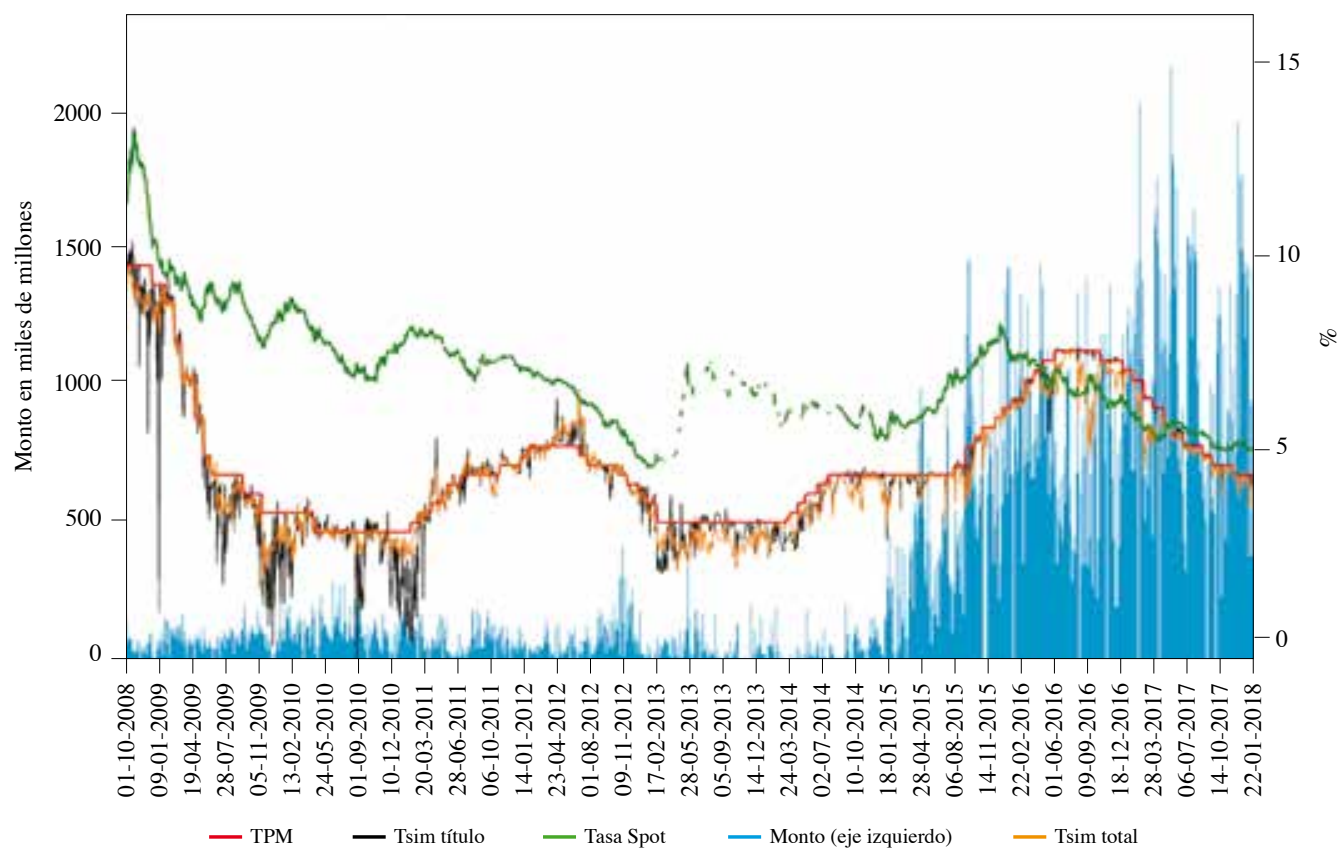

PESOS: JUL-24

Este título es uno de los más representativos de acuerdo con el monto negociado tanto en el rango R2 como en el R3. Los episodios en los que la Tsim del título se desvía más de la TPM son 2009, 2011, 2013, 2014, y parte del 2016 y 2017, en los cuales el margen del título es considerablemente más amplio que el margen total, lo que permite inferir que estarían asociados a estrategias para cubrir operaciones en corto en el mercado de contado.

23 Entre abril de 2017 y abril de 2018. 
A inicios de 2016, el monto transado en simultáneas sobre este título alcanza los niveles máximos, coincidiendo con una menor desviación de la Tsim frente a la TPM. En el segundo semestre de 2016 e inicios de 2017, los montos (aunque siguen siendo altos) disminuyen respecto a los máximos observados y la Tsim baja y se aleja de la TPM.

Durante el periodo de análisis, se identifica que algunos de los episodios en los que la Tsim del título se desvía más de la TPM coinciden con periodos en los que la tasa del mercado secundario aumenta temporalmente. Hay casos en los que esto no sucede, lo que podría dar indicios de que las expectativas de desvalorización de los títulos en el mercado de contado no siempre se materializan; el mayor apetito por referencias específicas a veces obedece a la cobertura de operaciones NDF sobre TES o a la segmentación del mercado (figura 5).

Figura 5: TFIT16240724

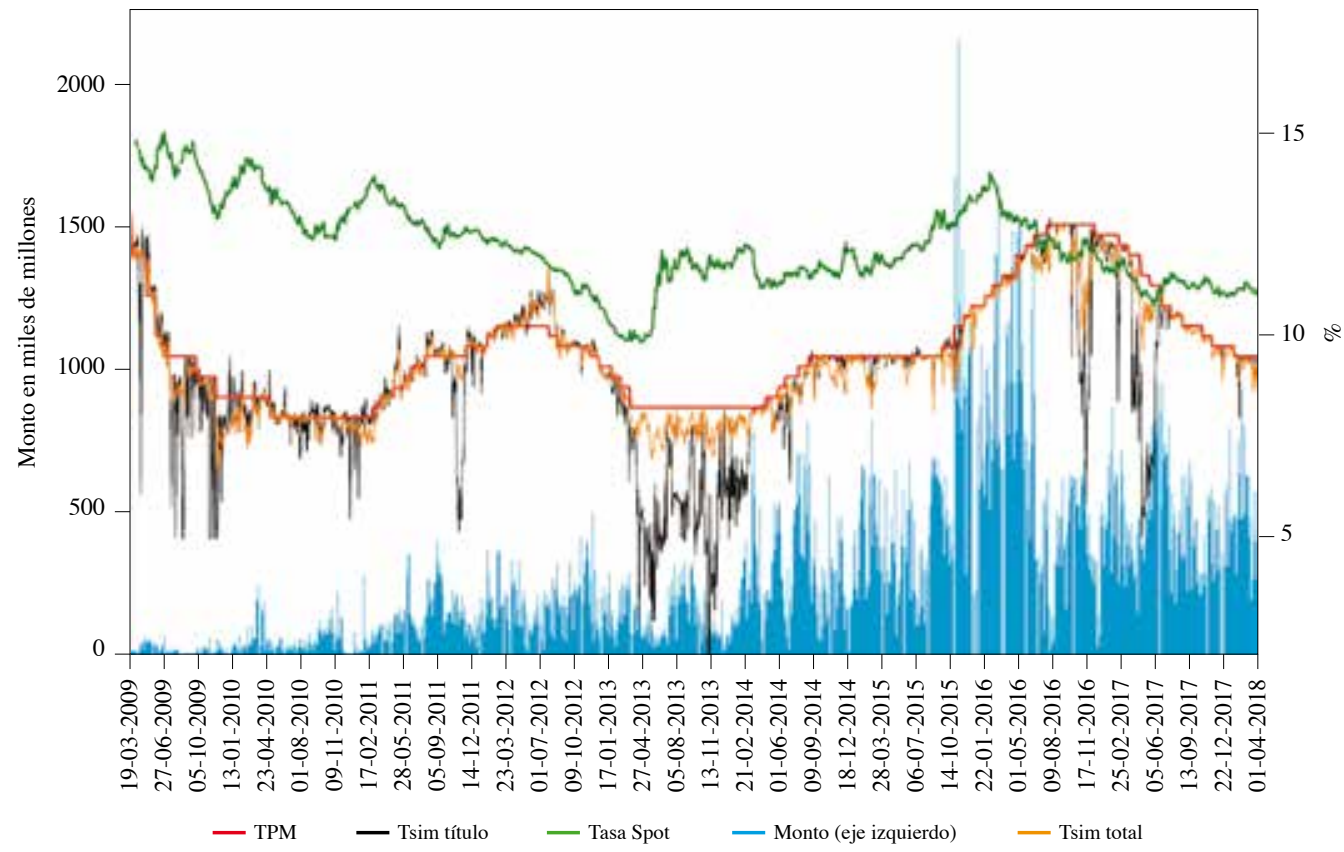

PESOS: SEP-30

Este título es uno de los más representativos de acuerdo con el monto negociado en el rango R3. Por lo general, la Tsim del título es significativamente más 
baja que la Tsim total, lo cual podría estar asociado a la baja liquidez de esta referencia tanto en el mercado de contado como en el de simultáneas, lo que hace más evidente las estrategias para cubrir operaciones en corto en el mercado de contado. La baja liquidez del bono obedece a que los principales tenedores son inversionistas extranjeros, quienes no negocian activamente en el mercado secundario de TES ni en el mercado de simultáneas.

Esta referencia no se transa todos los días en el mercado secundario, y su tasa de negociación en este presenta relativa estabilidad, factores que podrían dificultar la materialización de las expectativas de desvalorización (figura 6).

Figura 6: TFIT16180930

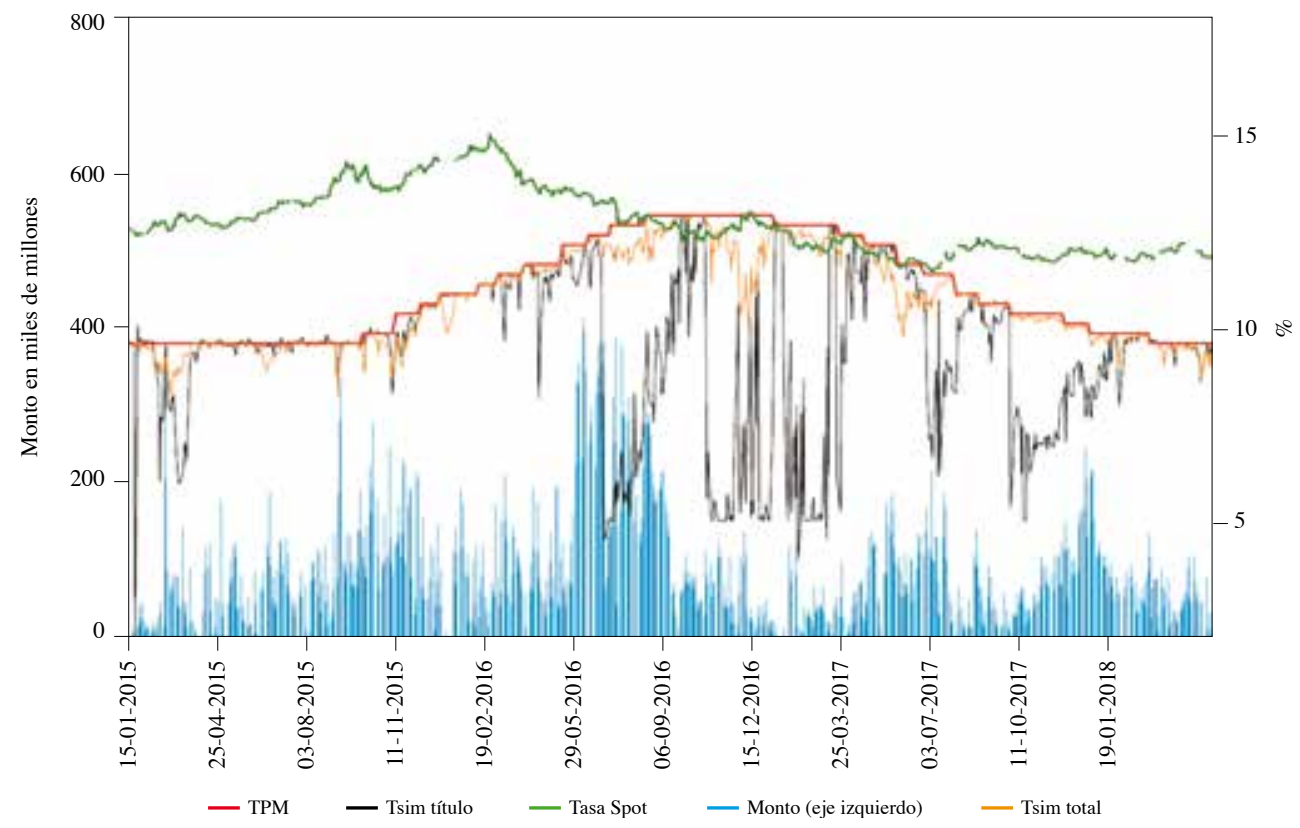

UVR: MAR-21

Su comportamiento es similar al de la referencia en pesos que vence en sep-30. Este título es uno de los más representativos de acuerdo con el monto negociado tanto en el rango R2 como en el R3. Por lo general, la Tsim del título es significativamente más baja que la Tsim total, lo cual podría estar asociado a la baja liquidez de esta referencia tanto en el mercado de contado como en el de simultáneas, lo que hace más evidente las estrategias para cubrir operaciones 
en corto en el mercado de contado. La baja liquidez del bono obedece a que los principales tenedores son fondos de pensiones obligatorias y cesantías, los cuales por su estrategia de inversión no negocian activamente en el mercado secundario de TES ni en el de simultáneas a través del SEN (mercado mayorista).

Al final del periodo de análisis el monto transado en el mercado de simultáneas aumentó relativamente y alcanzó los niveles máximos, lo que coincidió con una menor desviación de la Tsim del título frente a la TPM. Esto último podría obedecer a que los agentes ya no tenían expectativas de desvalorización (de tal manera que en el mercado de simultáneas disminuyó el apetito por esta referencia para cubrir posiciones cortas) o que ante el incremento del monto negociado, las estrategias para cubrir operaciones en corto fueron menos evidentes (figura 7).

Figura 7: TUVT10100321

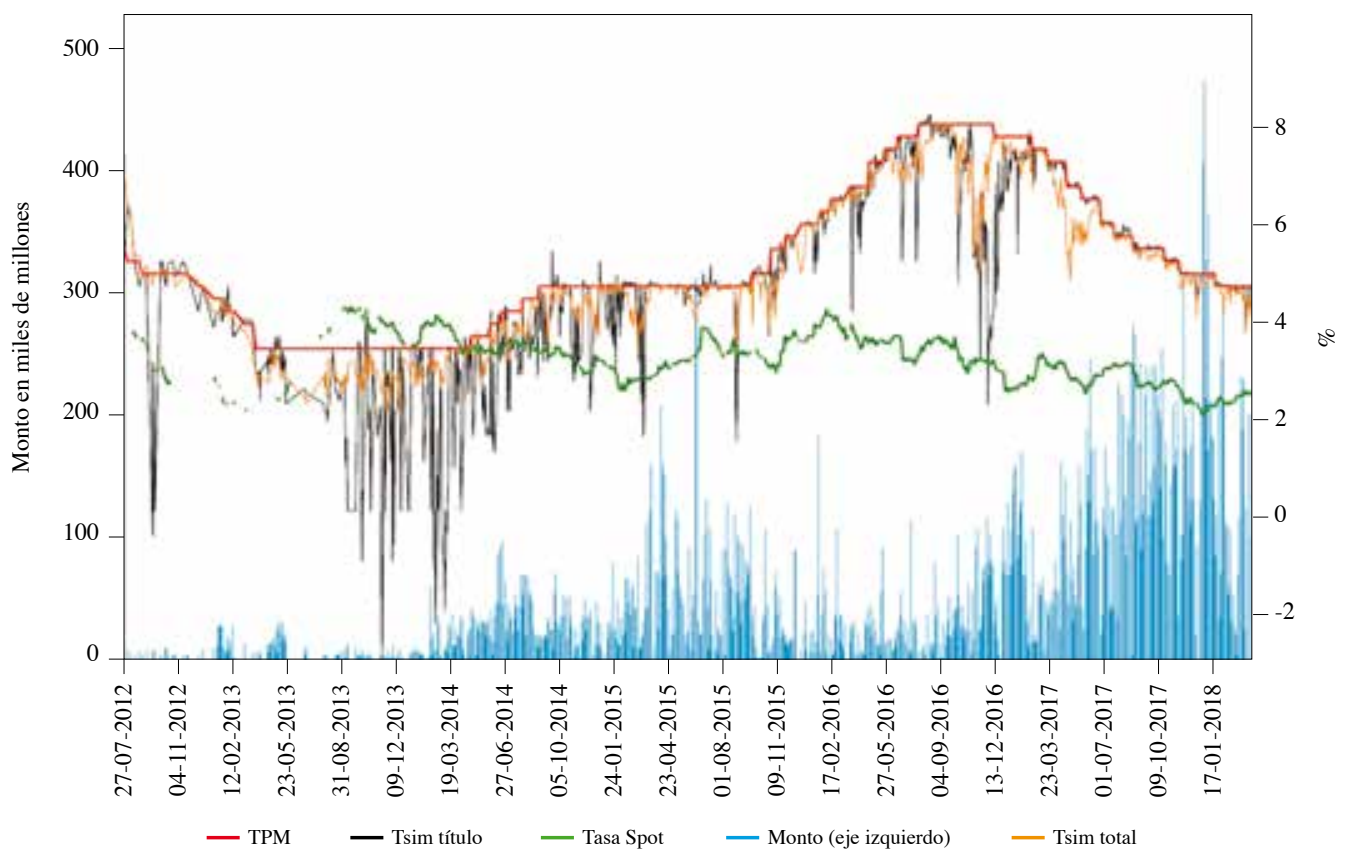

UVR: ABR-35

Este título es uno de los más representativos de acuerdo con el monto negociado en el rango R3. Dada su baja liquidez tanto en el mercado de simultáneas 
como en el de contado de TES, las estrategias para cubrir operaciones en corto son más evidentes y, por tanto, la Tsim del título se desvía significativamente de la Tsim total durante la mayor parte del periodo de análisis.

Los principales tenedores son fondos de pensiones y cesantías y aseguradoras, los cuales no negocian de forma activa en el mercado de TES ni en el de simultáneas, lo que hace que sea una referencia considerada como escasa. La tasa de rendimientos en el mercado secundario de TES presenta relativa estabilidad, lo que podría dificultar la materialización de las expectativas de desvalorización (figura 8).

Figura 8: TUVT20040435

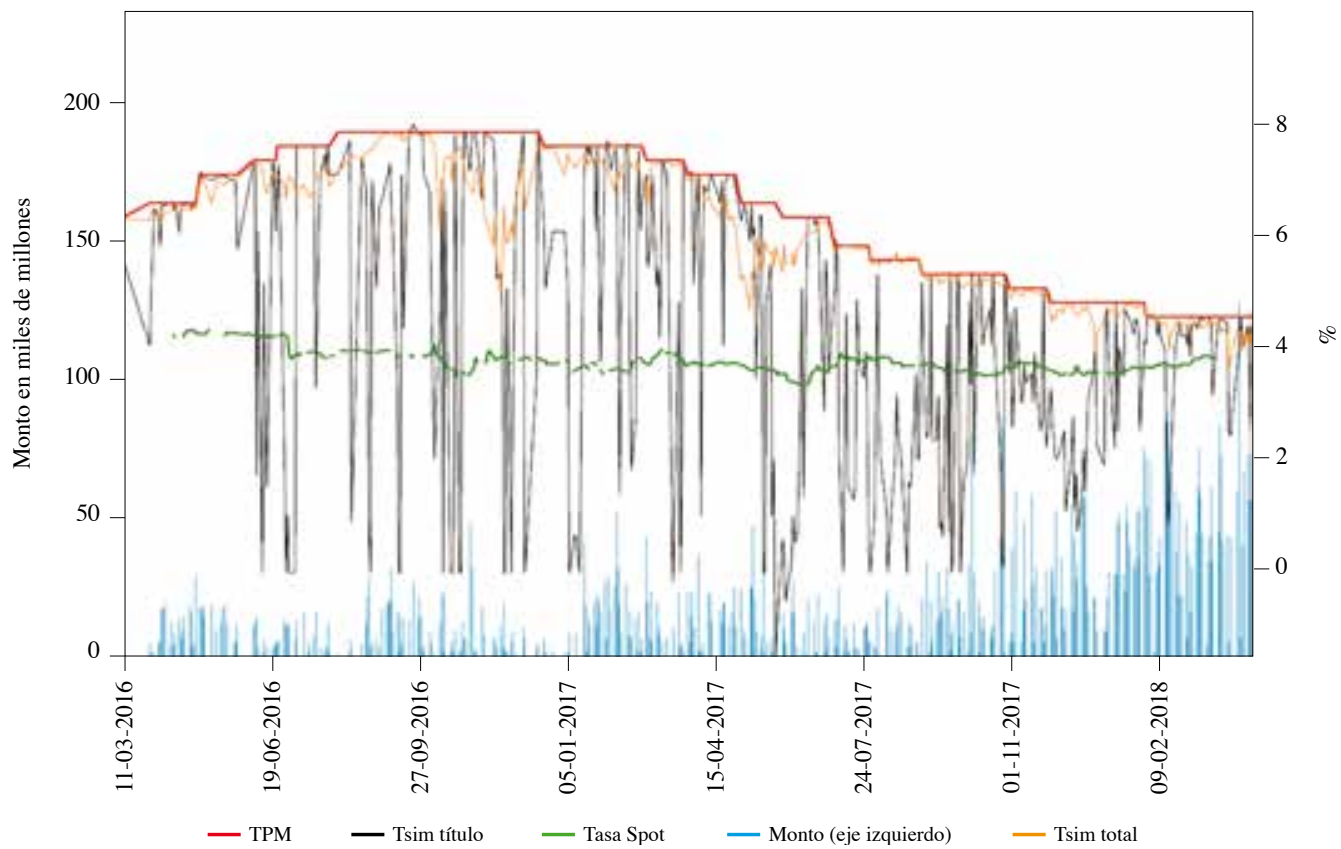




\section{Análisis estadístico}

Dado que la desviación de la Tsim frente a la TPM parece estar asociada tanto a las condiciones de liquidez en pesos como a la liquidez de los bonos en el mercado de simultáneas, se realizó un análisis estadístico para explorar si existe una relación intertemporal (rezagada, adelantada o contemporánea), entre el margen total y las variables asociadas a la liquidez en el mercado monetario ${ }^{24}$ (Anexo 1). En términos generales, una menor (mayor) liquidez en pesos debería generar presiones al alza (a la baja) sobre la Tsim. Por otro lado, un mayor volumen de operaciones con un título debería permitir que las desviaciones de la Tsim respecto a la TPM fueran menores. En efecto, los resultados muestran que el margen tiene una correlación positiva (se hace menos negativo) con mayores: cupos de la subasta del $\mathrm{BR}^{25}$, montos adjudicados en la subasta del $\mathrm{BR}^{26}$, porcentajes de utilización del cupo de la subasta del $\mathrm{BR}^{27}$ y depósitos de la Tesorería de la Nación ${ }^{28}$. Por otra parte, la relación es negativa y débil con los montos de las simultáneas ${ }^{29}$.

Con el propósito de determinar si el monto negociado en simultáneas presenta una correlación más fuerte con el margen por título, y si la disminución de la Tsim está relacionada con las estrategias en corto ante expectativas de desvalorizaciones de los TES, se tomaron los títulos más utilizados en las simultáneas pactadas dentro del rango R3 y se evaluaron las relaciones entre el margen por título con sus respectivas tasas en el mercado de contado y los montos negociados en simultáneas (tabla 1).

24 Las variables son el cupo, el monto adjudicado y la utilización del cupo de la subasta de repos de expansión del BR, los saldos de la Tesorería de la Nación en las cuentas de depósito del BR y el monto de las simultáneas negociadas en el SEN (como una medida de profundidad del mercado).

25 La máxima correlación ocurre cuando el margen tiene un rezago de dos periodos frente al cupo $(41,68 \%)$.

26 La máxima correlación ocurre sin rezagos ni adelantos, lo que indica una relación contemporánea $(46,78 \%)$.

27 La máxima correlación ocurre cuando el margen tiene un adelanto de un periodo frente a la utilización del cupo $(30,5 \%)$

28 La máxima correlación ocurre sin rezagos ni adelantos, lo que indica una relación contemporánea $(29,48 \%)$.

29 La máxima correlación ocurre cuando el margen tiene un rezago de 10 periodos frente al monto $(-15,89 \%)$. 
Tabla 1: Margen por título

\begin{tabular}{|l|c|}
\hline \multicolumn{2}{|c|}{ Margen por título vs. Tasa mercado contado: Positiva } \\
\hline Referencia & Máxima corrección (x) \\
\hline TES en pesos jul-20 & $+21,02 \%$ \\
\hline TES en pesos jul-24 & $+17,2 \%$ \\
\hline TES en pesos sep-30 & $+25,15 \%$ \\
\hline TES en UVR mar-21 & $-24,11 \%$ \\
\hline TES en UVR abr-35 & $-24,13 \%$ \\
\hline
\end{tabular}

\begin{tabular}{|l|c|}
\hline \multicolumn{2}{|c|}{ Margen por título vs. Monto en simultáneas: Positiva } \\
\hline Referencia & Máxima corrección (x) \\
\hline TES en pesos jul-20 & $+37,84 \%$ \\
\hline TES en pesos jul-24 & $+43,5 \%$ \\
\hline TES en pesos sep-30 & $+19,72 \%$ \\
\hline TES en UVR mar-21 & $-19,1 \%$ \\
\hline TES en UVR abr-35 & $+20,69 \%$ \\
\hline
\end{tabular}

Los resultados muestran que la correlación entre el margen y el volumen negociado fue positiva, lo que indica que entre mayor es el volumen negociado, la Tsim se aleja menos de la TPM, lo que va en línea con el análisis por título, en el que se encontró que las estrategias para cubrir operaciones en corto son más notorias cuando un título presenta menor liquidez en el mercado de simultáneas. Esto contrasta con el resultado hallado en el ejercicio realizado con el margen total, en el que la relación era negativa y más débil, lo que podría estar explicado por el comportamiento heterogéneo de los títulos.

Al analizar por título la correlación entre el margen y la tasa de contado, se encuentra que en la mayoría de $\operatorname{los}_{\operatorname{casos}^{30}} \mathrm{es} \mathrm{positiva}^{31}$. Esto contradice la hipótesis que estipula que, ante expectativas de desvalorizaciones de los TES, la Tsim es cada vez menor. Este resultado puede obedecer a que no siempre se materializan

30 Excepto en los TES en UVR que vencen el 21 de marzo.

31 La relación positiva entre estas variables reflejaría que a medida que la tasa de contado en el mercado secundario aumenta (desvalorizaciones en los TES), la Tsim se acerca desde abajo a la TPM o la sobrepasa. 
las expectativas de desvalorizaciones de los agentes que motivaron la toma de posiciones cortas en el mercado de contado, a que las simultáneas tienen como objetivo cubrir operaciones de NDF sobre TES o a la segmentación del mercado.

Por otra parte, se realiza una regresión entre el margen total (variable dependiente) y las variables asociadas a la liquidez en pesos en el mercado monetario, esperando que la porción no explicada por el modelo incorpore el efecto de la posible búsqueda de títulos para cubrir estrategias en corto. El modelo con mejor ajuste y con el mayor número de variables con significancia estadística incluye el cupo de la subasta de repos del BR con rezago de un periodo, el monto adjudicado el día de la subasta, la utilización del cupo con un periodo de rezago, y el porcentaje del monto negociado en el mercado de simultáneas en el rango $\mathrm{R} 2$ en relación con el monto total ${ }^{32}$ (Anexo 2). Adicionalmente, se estima un modelo GARCH $(1,1)^{33}$ para corregir problemas con los residuales del modelo original $^{34}$ (anexos 3 y 4). El modelo resultante es el siguiente:

$$
\begin{aligned}
& \text { Margen_t } \mathrm{t}=\beta_{0}+\beta_{1} \log (\text { cupo })_{(\mathrm{t}-1)}+\beta_{2} \log (\text { adjudicado })_{\mathrm{t}}+\beta_{3} \\
& \text { utilización del cupo }(\mathrm{t}-1)+\beta_{4} \% \text { monto simultáneas } \mathrm{R} 2_{\mathrm{t}}+\varepsilon_{\mathrm{t}}
\end{aligned}
$$

Los signos de los coeficientes (todos positivos) son congruentes con la intuición. Un margen menos negativo está asociado a mayores cupos del BR (que refleja que el BR ha identificado mayores necesidades de recursos), y a mayor utilización de los cupos. Con relación a los montos de simultáneas en el rango R2 -que concentra la mayor porción del monto negociado en simultáneas- el coeficiente positivo corrobora la intuición de que bajo condiciones de liquidez adecuada las desviaciones negativas de la Tsim sobre la TPM disminuyen (el margen se hace menos negativo).

Dado que en el rango R2 se concentran las operaciones de simultáneas cuyas tasas presentan menores desviaciones frente a la TPM, resulta interesante tratar de identificar si las operaciones de simultáneas pactadas en este rango

32 No se incluyeron los depósitos de la Tesorería debido a que su comportamiento está incorporado en el cálculo del cupo de la subasta de repos.

33 Para la selección del número de rezagos se utilizaron los criterios de información.

34 No hay evidencia de que los datos pertenezcan a una distribución normal. Hay presencia de heterocedasticidad contemporánea de los errores, autocorrelación intertemporal en la serie de los residuos y presencia de efecto ARCH. 
reflejan de mejor manera las condiciones de liquidez del mercado monetario. Con este fin, se estima un modelo usando como variable dependiente el margen del rango R2 (Margen_R2) y como explicativas las variables de liquidez del modelo antes descrito. Las pruebas estadísticas sobre los residuales ${ }^{35}$ muestran los mismos resultados que el modelo del margen total, por lo que se estimó un modelo GARCH $(2,2)$ (anexo 5):

$$
\begin{gathered}
\text { Margen_R } 2_{\mathrm{t}}=\beta_{0}+\beta_{1} \log (\text { cupo })_{(\mathrm{t}-1)}+\beta_{2} \log (\text { adjudicado }) \\
\mathrm{t}+\beta_{3} \text { utilización del cupo }{ }_{(\mathrm{t}-1)}+\beta_{4} \% \text { monto simultáneas } \mathrm{R} 2_{\mathrm{t}}+\varepsilon_{\mathrm{t}}
\end{gathered}
$$

El ajuste de este modelo es mejor respecto al modelo en el que la variable dependiente es el margen total, lo que corrobora la hipótesis de que el margen de las simultáneas pactadas en el rango $\mathrm{R} 2$ refleja con mayor precisión las condiciones de liquidez del mercado monetario frente al margen total ${ }^{36}$.

Finalmente, se estimó una regresión con el objetivo de evaluar la relación entre el margen del rango R1 (variable dependiente) y las variables de liquidez (anexo 6).

$$
\begin{gathered}
\text { Margen_R } 1_{\mathrm{t}}=\beta_{0}+\beta_{1} \log (\text { cupo })_{(\mathrm{t}-1)}+\beta_{2} \log (\text { adjudicado }) \\
+\beta_{3} \text { utilización del cupo } \mathrm{t}_{\mathrm{t}-1)}+\beta_{4} \% \text { monto simultáneas } \mathrm{R} 2_{\mathrm{t}}+\varepsilon_{\mathrm{t}}
\end{gathered}
$$

En este caso, el modelo cumplió con los supuestos de los residuales que en anteriores modelos fueron corregidos con la estimación del $\mathrm{GARCH}^{37}$, por lo cual no fue necesario usar un método distinto a los mínimos cuadrados ordinarios. Sin embargo, el ajuste del modelo fue muy bajo (11\%) y dos de las variables explicativas

35 No hay evidencia de que los datos pertenezcan a una distribución normal. Hay presencia de heterocedasticidad contemporánea de los errores, autocorrelación intertemporal en la serie de los residuos y presencia de efecto ARCH.

36 En el nuevo modelo, los signos de los coeficientes de las variables explicativas siguen siendo iguales a los del modelo en el que la variable dependiente es el margen total y se mantiene la significancia estadística de las variables.

37 Al estimar los GARCH para los modelos anteriores se corrigió la heterocedasticidad contemporánea de los errores y la presencia de efecto ARCH. Aunque el modelo con el margen R1 no violaba estos supuestos -por lo cual no hubo necesidad de usar otro método- no hay evidencia de que los datos pertenezcan a una distribución normal y además hay presencia de autocorrelación intertemporal en la serie de los residuos. 
asociadas a la liquidez no presentaron significancia estadística (monto adjudicado y utilización del cupo). Esto podría obedecer a que en este rango se concentran muy pocas operaciones (en promedio el $9 \%$ del monto total diario).

\section{Análisis de escenarios con montos representativos a tasas bajas}

En la figura 9 se encuentra que existen episodios en los cuales el monto transado en el rango R3 aumenta de forma significativa por encima del $34 \%$ (promedio de $13 \%$ más una desviación estándar de $21 \%$ ). Teniendo en cuenta que la acumulación de operaciones a tasas muy bajas puede ser atípica y no necesariamente relacionada con condiciones de liquidez, sino con expectativas de desvalorizaciones de los TES, se comparó el comportamiento del monto negociado en el rango R3 con algunas variables asociadas a la percepción de riesgo hacia el mercado de TES como el VIX, el MOVE, los CDS a 5 años, y el IDXTES -que corresponde a un índice agregado de precios representativo del mercado de deuda pública-.

Figura 9:

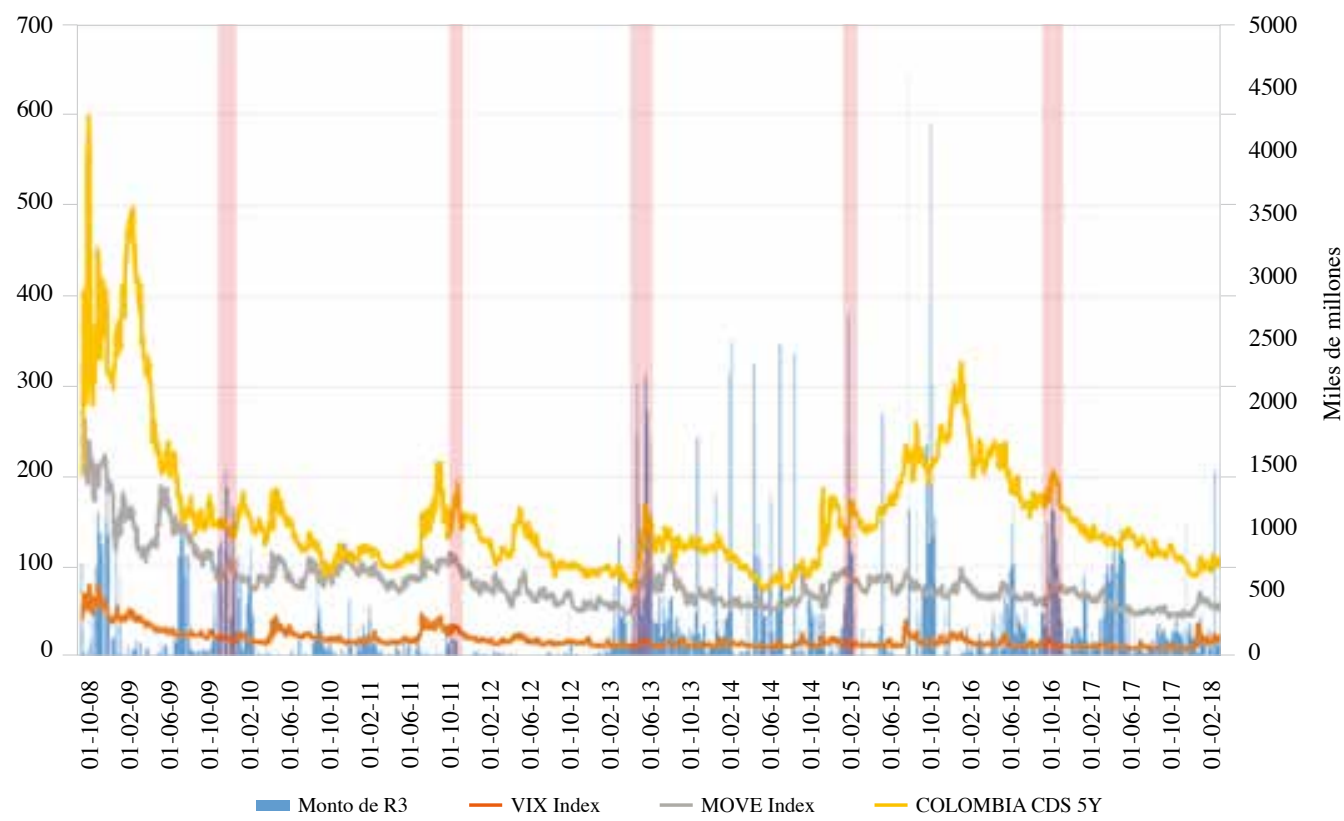




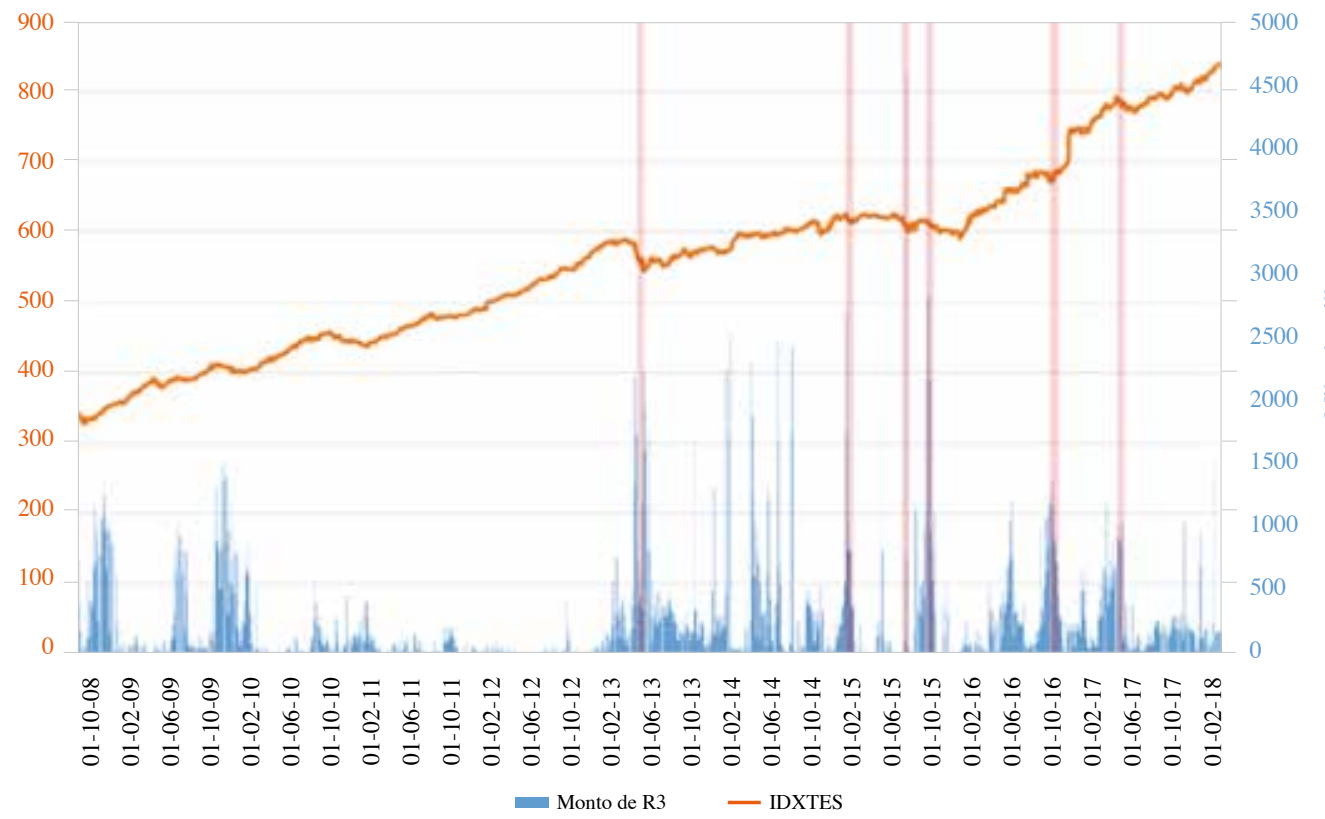

Fuente: cálculos propios; base de datos SEN y Bloomberg.

Al parecer, algunos episodios en los que aumenta el monto del rango negociado en el rango R3, coinciden con incrementos del VIX, el MOVE y el CDS o con una disminución del IDXTES. Aunque no se realiza un análisis econométrico más detallado sobre esta relación, su existencia podría implicar que el monitoreo de las negociaciones en el rango $\mathrm{R} 3$ posiblemente serviría para generar un indicador de alerta temprana de movimientos de desvalorización en el mercado de TES o de incertidumbre.

\section{Conclusiones}

- El $70 \%$ de los días del periodo analizado, el margen entre la tasa promedio ponderada por monto de las simultáneas y la TPM oscila entre $\pm 1 \sigma$.

- En promedio, el $78 \%$ del monto diario negociado en simultáneas se concentra en operaciones cuyo margen entre la tasa promedio ponderada por monto de las simultáneas y la TPM oscila entre $\pm 1 \sigma$.

- El 13\% del monto total transado diariamente, corresponde a operaciones cuyos márgenes frente a la TPM son inferiores al valor histórico de - $1 \sigma$. Estas operaciones pueden estar asociadas a casos puntuales de excesos de liquidez 
en pesos o a las necesidades de cubrir estrategias en corto en el mercado de TES. En este último caso, es posible que cuando un agente necesite un título considerado "escaso", esté dispuesto a otorgar la liquidez a tasas bajas.

- A medida que disminuyen los montos negociados en simultáneas sobre un título, sus tasas en el mercado de liquidez tienden a ser más bajas y más alejadas de la TPM. Esto corrobora la hipótesis de que las estrategias para cubrir operaciones en corto son más evidentes cuando la liquidez del título es baja.

- Los montos pactados en las simultáneas sobre TES en pesos son mayores y sus tasas en simultáneas son más cercanas a la TPM en comparación con las operaciones sobre TES en UVR.

- Los títulos cuyas tasas en simultáneas son más bajas en comparación con la TPM, corresponden a aquellos que son considerados "escasos" en el mercado de simultáneas. La escasez puede asociarse a que sus principales tenedores son fondos de pensiones y cesantías, inversionistas extranjeros y el BR, entre otros, cuyas estrategias no contemplan una negociación activa de títulos. La escasez también puede obedecer a que las entidades que poseen los títulos no tienen necesidades de liquidez, y, por tanto, no acuden al mercado de simultáneas.

- Al analizar los márgenes diarios de las operaciones que se ubican dentro del rango de $\pm 1 \sigma$, se encuentra que están relacionados con variables asociadas a la liquidez del mercado monetario local. Cuando se incluyen las operaciones por fuera de ese rango, la relación con las variables de la liquidez se debilita.

- Altos volúmenes de operaciones de simultáneas a tasas bajas podrían indicar expectativas de desvalorizaciones de los TES, lo que amerita monitorear el monto de estas operaciones "inusuales" como una señal de alerta temprana del mercado de TES. 


\section{Anexos}

Anexo 1. Correlogramas ${ }^{38}$

Figura 1: Correlograma entre el margen total y los montos de las simultáneas

Cross Correlogram of SPREAD and LOG(MONTO)

\begin{tabular}{|c|c|c|c|c|}
\hline \multicolumn{5}{|c|}{$\begin{array}{l}\text { Date: } 09 / 23 / 18 \text { Time: } 20: 38 \\
\text { Sample: } 10 / 01 / 20083 / 28 / 2018 \\
\text { Included observations: } 2314 \\
\text { Correlations are asymptotically consistent approximations }\end{array}$} \\
\hline SPREAD,LOG(MONTO)(- & -i) SPREAD,LOG(MONTO)(+ & $\mathbf{i}$ & lag & lead \\
\hline 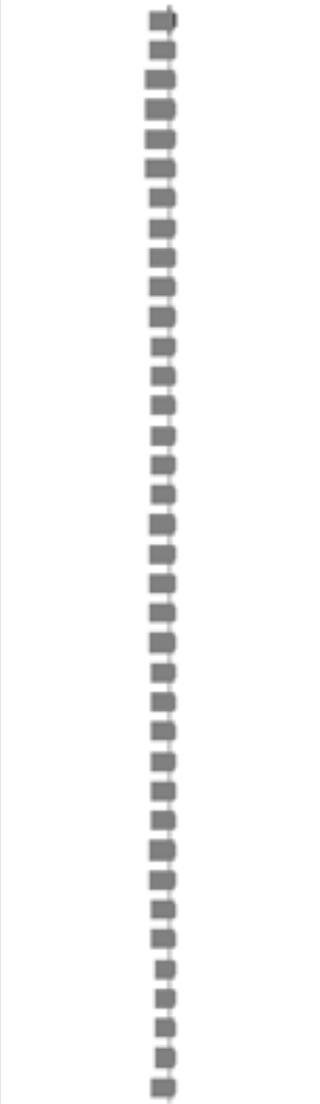 & 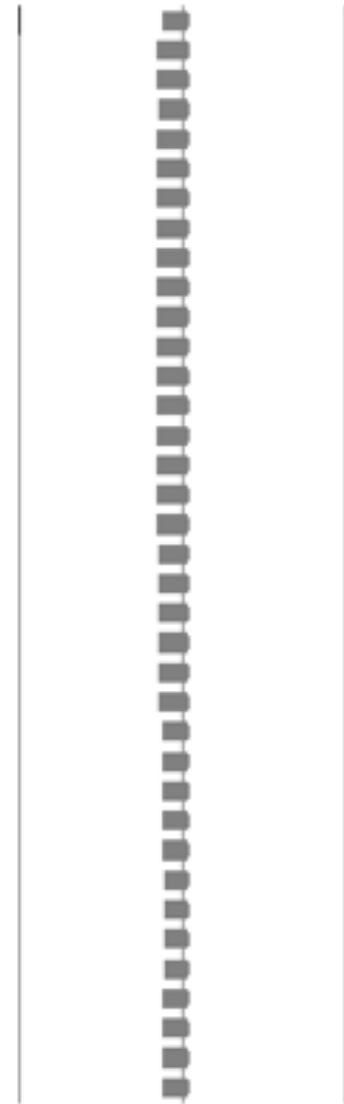 & \begin{tabular}{|r}
0 \\
1 \\
2 \\
3 \\
4 \\
5 \\
6 \\
7 \\
8 \\
9 \\
10 \\
11 \\
12 \\
13 \\
14 \\
15 \\
16 \\
17 \\
18 \\
19 \\
20 \\
21 \\
22 \\
23 \\
24 \\
25 \\
26 \\
27 \\
28 \\
29 \\
30 \\
31 \\
32 \\
33 \\
34 \\
35 \\
36
\end{tabular} & $\begin{array}{l}-0.1212 \\
-0.1291 \\
-0.1421 \\
-0.1400 \\
-0.1323 \\
-0.1399 \\
-0.1306 \\
-0.1301 \\
-0.1293 \\
-0.1248 \\
-0.1194 \\
-0.1113 \\
-0.1101 \\
-0.1113 \\
-0.1078 \\
-0.1097 \\
-0.1141 \\
-0.1219 \\
-0.1189 \\
-0.1178 \\
-0.1179 \\
-0.1168 \\
-0.1145 \\
-0.1137 \\
-0.1089 \\
-0.1081 \\
-0.1117 \\
-0.1113 \\
-0.1178 \\
-0.1162 \\
-0.1120 \\
-0.1053 \\
-0.0963 \\
-0.0963 \\
-0.0956 \\
-0.0971 \\
-0.0984\end{array}$ & $\begin{array}{l}-0.1212 \\
-0.1520 \\
-0.1522 \\
-0.1469 \\
-0.1477 \\
-0.1497 \\
-0.1517 \\
-0.1509 \\
-0.1561 \\
-0.1568 \\
-0.1589 \\
-0.1544 \\
-0.1520 \\
-0.1556 \\
-0.1527 \\
-0.1528 \\
-0.1519 \\
-0.1485 \\
-0.1393 \\
-0.1455 \\
-0.1383 \\
-0.1345 \\
-0.1379 \\
-0.1356 \\
-0.1296 \\
-0.1280 \\
-0.1224 \\
-0.1180 \\
-0.1171 \\
-0.1080 \\
-0.1061 \\
-0.1128 \\
-0.1126 \\
-0.1168 \\
-0.1215 \\
-0.1281 \\
-0.1298\end{array}$ \\
\hline
\end{tabular}

38 La columna "Lag" indica que el margen total está adelantado en $i$ periodos (número de días en este caso) con respecto a la variable de análisis (montos de las simultáneas, cupo de la 
Figura 2: Correlograma entre el margen total y el cupo de la subasta del BR Cross Correlogram of SPREAD and LOG(CUPO)

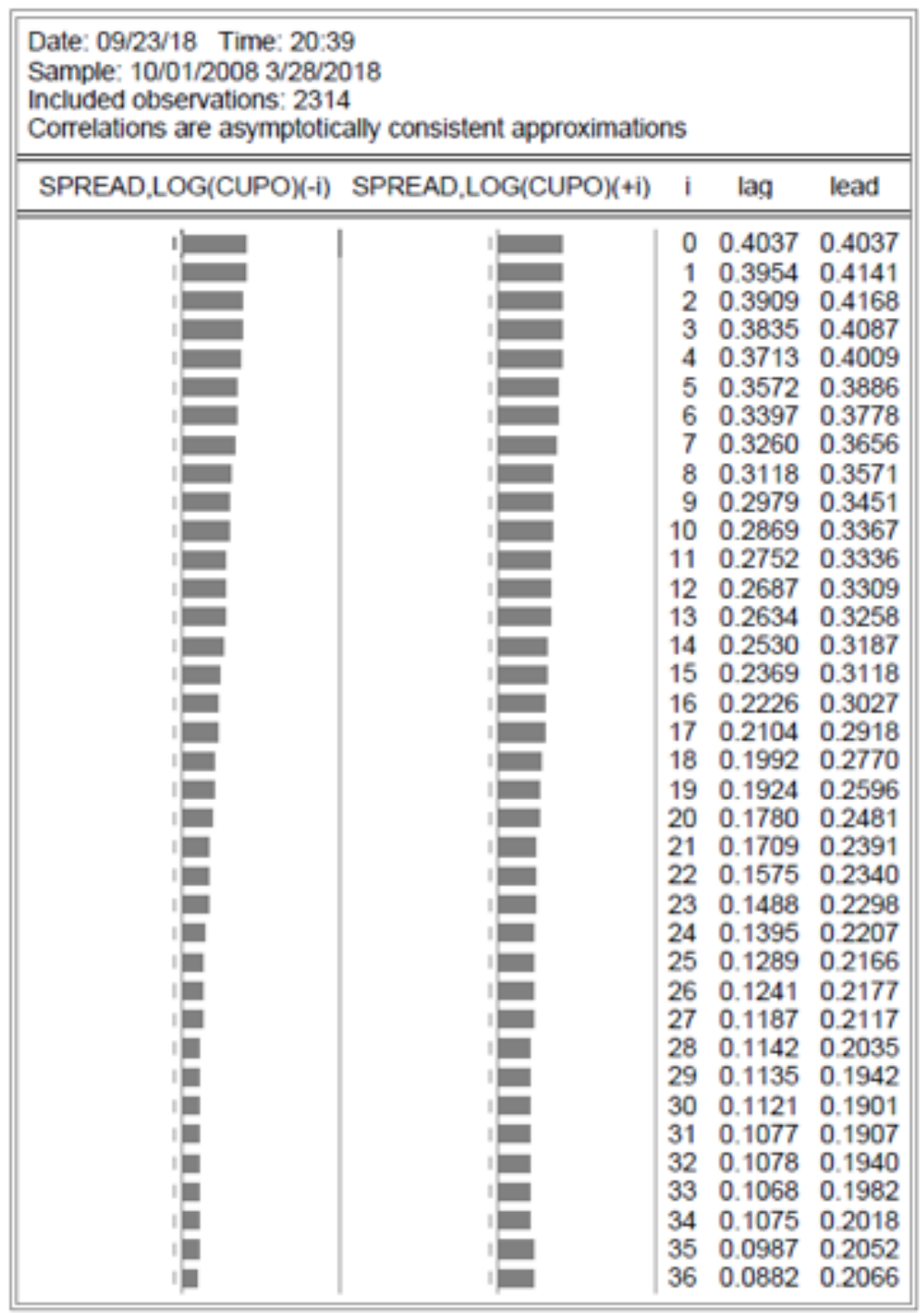

subasta del BR, monto adjudicado en la subasta del BR, utilización del cupo de la subasta del BR y depósitos de la Tesorería de la Nación). De forma contraria, la columna "Lead" indica que el margen total está rezagado en $i$ periodos con respecto a la variable de análisis. 
Figura 3: Correlograma entre el margen total y el monto adjudicado en la subasta del BR Cross Correlogram of SPREAD and LOG(ADJUDICADO)

\begin{tabular}{|c|c|c|c|c|}
\hline \multicolumn{5}{|c|}{$\begin{array}{l}\text { Date: 09/23/18 Time: } 20: 40 \\
\text { Sample: } 10 / 01 / 20083 / 28 / 2018 \\
\text { Included observations: } 2314 \\
\text { Correlations are asymptotically consistent approximations }\end{array}$} \\
\hline SPREAD,LOG(ADJUDIC & SPREAD,LOG(ADJUDIC & i & lag & lead \\
\hline $\begin{array}{ll} \\
\\
\end{array}$ & 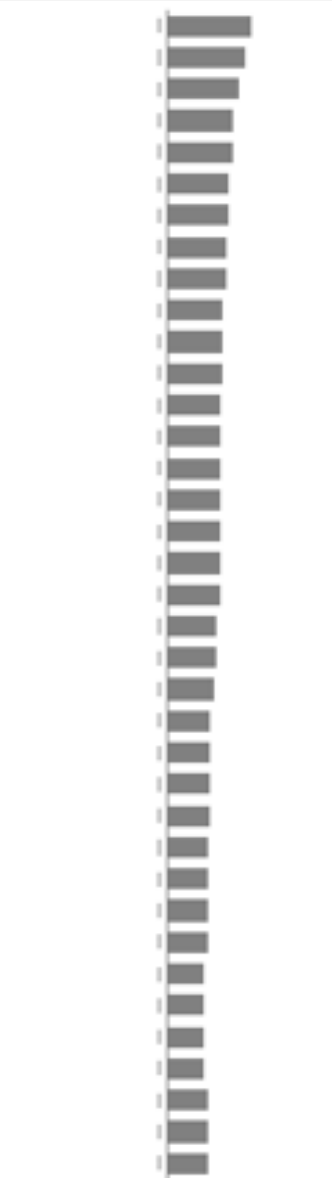 & $\begin{array}{r}0 \\
1 \\
2 \\
3 \\
4 \\
5 \\
6 \\
7 \\
8 \\
9 \\
10 \\
11 \\
12 \\
13 \\
14 \\
15 \\
16 \\
17 \\
18 \\
19 \\
20 \\
21 \\
22 \\
23 \\
24 \\
25 \\
26 \\
27 \\
28 \\
29 \\
30 \\
31 \\
32 \\
33 \\
34 \\
35 \\
36\end{array}$ & $\begin{array}{l}0.4678 \\
0.4648 \\
0.4422 \\
0.4155 \\
0.3897 \\
0.3684 \\
0.3443 \\
0.3279 \\
0.3206 \\
0.3139 \\
0.3015 \\
0.2828 \\
0.2667 \\
0.2508 \\
0.2411 \\
0.2285 \\
0.2255 \\
0.2172 \\
0.2086 \\
0.2029 \\
0.1936 \\
0.1832 \\
0.1694 \\
0.1551 \\
0.1491 \\
0.1409 \\
0.1376 \\
0.1257 \\
0.1210 \\
0.1199 \\
0.1190 \\
0.1255 \\
0.1200 \\
0.1145 \\
0.1051 \\
0.0948 \\
0.0914\end{array}$ & $\begin{array}{l}0.4678 \\
0.4349 \\
0.4035 \\
0.3758 \\
0.3617 \\
0.3593 \\
0.3460 \\
0.3342 \\
0.3306 \\
0.3168 \\
0.3117 \\
0.3057 \\
0.2893 \\
0.2872 \\
0.2906 \\
0.2941 \\
0.2880 \\
0.2822 \\
0.2823 \\
0.2706 \\
0.2686 \\
0.2536 \\
0.2387 \\
0.2384 \\
0.2298 \\
0.2321 \\
0.2288 \\
0.2199 \\
0.2141 \\
0.2090 \\
0.1980 \\
0.1922 \\
0.1968 \\
0.2039 \\
0.2145 \\
0.2212 \\
0.2150\end{array}$ \\
\hline
\end{tabular}


Figura 4: Correlograma entre el margen total y la utilización del cupo de la subasta del BR Cross Correlogram of SPREAD and UTILIZACION_CUPO

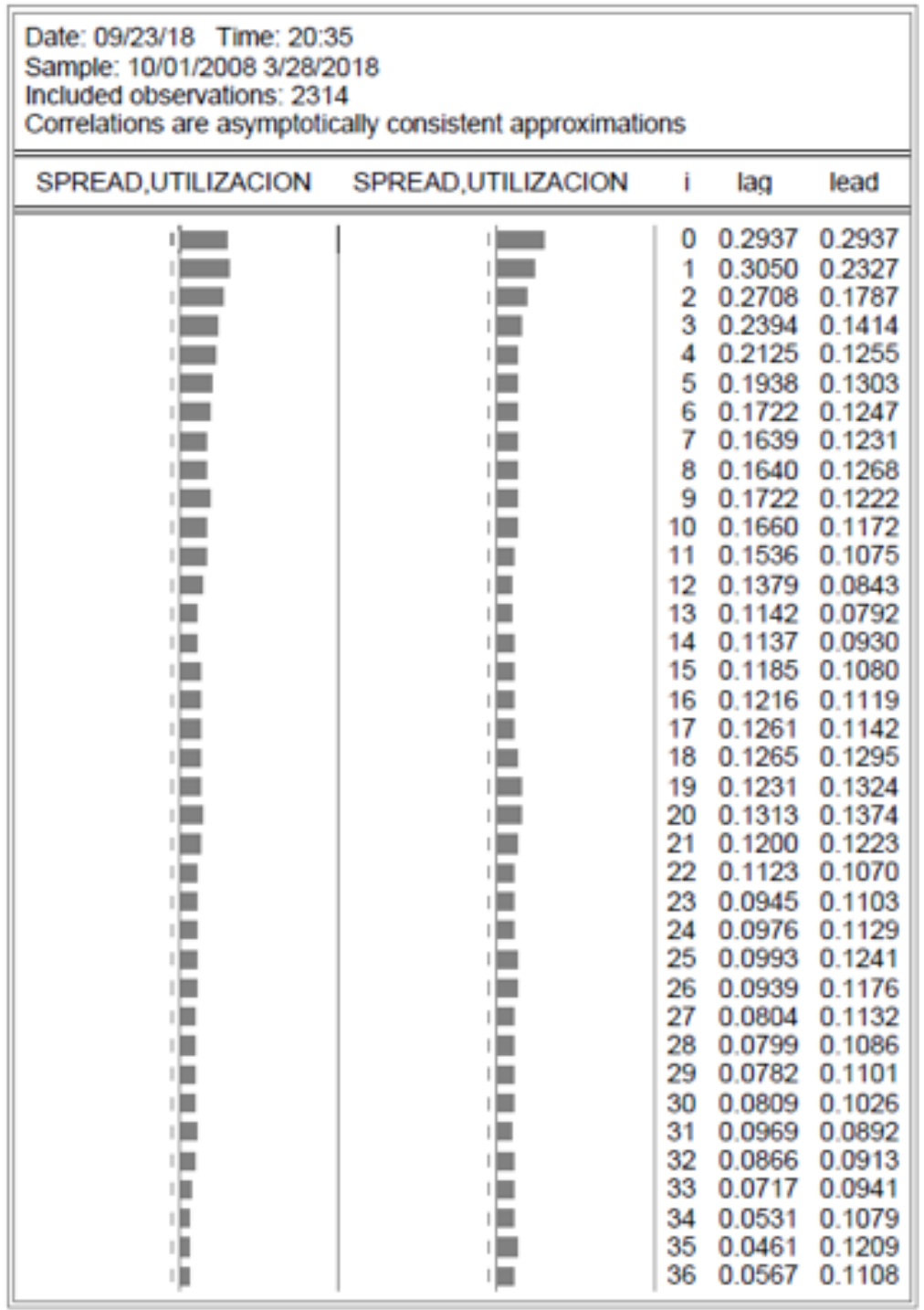


Figura 5: Correlograma entre el margen total y los depósitos de la Tesorería de la Nación Cross Correlogram of SPREAD and LOG(DEPOSITOS_TN)

\begin{tabular}{|c|c|c|c|c|}
\hline \multicolumn{5}{|c|}{$\begin{array}{l}\text { Date: 09/23/18 Time: } 20: 41 \\
\text { Sample: } 10 / 01 / 2008 \text { 3/28/2018 } \\
\text { Included observations: } 2312 \\
\text { Correlations are asymptotically consistent approximations }\end{array}$} \\
\hline SPREAD,LOG(DEPOSIT & SPREAD,LOG(DEPOSIT & $i$ & lag & lead \\
\hline בש: & שבי & \begin{tabular}{|r}
0 \\
1 \\
2 \\
3 \\
4 \\
5 \\
6 \\
7 \\
8 \\
9 \\
10 \\
11 \\
12 \\
13 \\
14 \\
15 \\
16 \\
17 \\
18 \\
19 \\
20 \\
21 \\
22 \\
23 \\
24 \\
25 \\
26 \\
27 \\
28 \\
29 \\
30 \\
31 \\
32 \\
33 \\
34 \\
35 \\
36
\end{tabular} & $\begin{array}{l}0.2948 \\
0.2883 \\
0.2764 \\
0.2613 \\
0.2455 \\
0.2309 \\
0.2169 \\
0.2037 \\
0.1903 \\
0.1775 \\
0.1672 \\
0.1585 \\
0.1473 \\
0.1376 \\
0.1311 \\
0.1250 \\
0.1178 \\
0.1107 \\
0.1018 \\
0.0934 \\
0.0860 \\
0.0800 \\
0.0731 \\
0.0679 \\
0.0616 \\
0.0559 \\
0.0521 \\
0.0477 \\
0.0447 \\
0.0435 \\
0.0437 \\
0.0444 \\
0.0450 \\
0.0446 \\
0.0419 \\
0.0383 \\
0.0345\end{array}$ & $\begin{array}{l}0.2948 \\
0.2941 \\
0.2912 \\
0.2886 \\
0.2876 \\
0.2872 \\
0.2851 \\
0.2825 \\
0.2808 \\
0.2778 \\
0.2739 \\
0.2698 \\
0.2694 \\
0.2711 \\
0.2711 \\
0.2705 \\
0.2698 \\
0.2690 \\
0.2695 \\
0.2701 \\
0.2692 \\
0.2662 \\
0.2647 \\
0.2616 \\
0.2598 \\
0.2573 \\
0.2558 \\
0.2519 \\
0.2493 \\
0.2473 \\
0.2441 \\
0.2409 \\
0.2378 \\
0.2371 \\
0.2367 \\
0.2351 \\
0.2316\end{array}$ \\
\hline
\end{tabular}




\section{Anexo 2. Modelo margen total}

$$
\begin{gathered}
\text { Margen }_{\mathrm{t}}=\beta_{0}+\beta_{1} \log \left(\text { cupo }_{(\mathrm{t}-1)}+\beta_{2} \log (\text { adjudicado })_{\mathrm{t}}+\beta_{3}\right. \\
\text { utilización del cupo } \\
(\mathrm{t}-1)
\end{gathered}
$$

Tabla 1

Dependent Variable: MARGEN

Method: Least Squares

Date: $12 / 0818$ Time: 10:12

Sample (adjusted): 10/02/2008 3/28/2018

Included observations: 2297 after adjustments

HAC standard errors \& covariance (Bartlett kernel, Newey-West foxed bandwidth $=9.0000$ )

\begin{tabular}{lrlrr}
\hline \hline \multicolumn{1}{c}{ Variable } & Coefficient & Std. Error & 1-Statistic & Prob. \\
\hline \hline \multicolumn{1}{c}{ C } & -439.7256 & 49.18819 & -8.939658 & 0.0000 \\
LOG(CUPO(-1)) & 12.74690 & 3.742772 & 3.405738 & 0.0007 \\
LOG(ADUUDICADO) & 11.69935 & 1.636664 & 7.148294 & 0.0000 \\
UTLIZACION_CUPO(-1) & 29.13538 & 4.057986 & 7.179763 & 0.0000 \\
$\quad$ MONTO_R2 & 24.38801 & 10.38277 & 2.348892 & 0.0189 \\
\hline \hline R-squared & 0.256940 & Mean dependent var & -25.30370 \\
Adjusted R-squared & 0.255643 & S.D. dependent var & 37.83373 \\
S.E. of regression & 32.64147 & Akaike info criterion & 9.811219 \\
Sum squared resid & 2442047. & Scmwarz criterion & 9.823712 \\
Log likelihood & -11263.18 & Hannan-Quinn criter. & 9.815774 \\
F-statistic & 198.1354 & Durbin-Watson stat & 0.294250 \\
Prob(F-statistic) & 0.000000 & Wald F-statistic & 74.39661 \\
Prob(Wald F-statistic) & 0.000000 & & & \\
\hline \hline
\end{tabular}




\section{Anexo 3. Pruebas estadísticas del Modelo margen total}

Figura 6: Prueba de normalidad

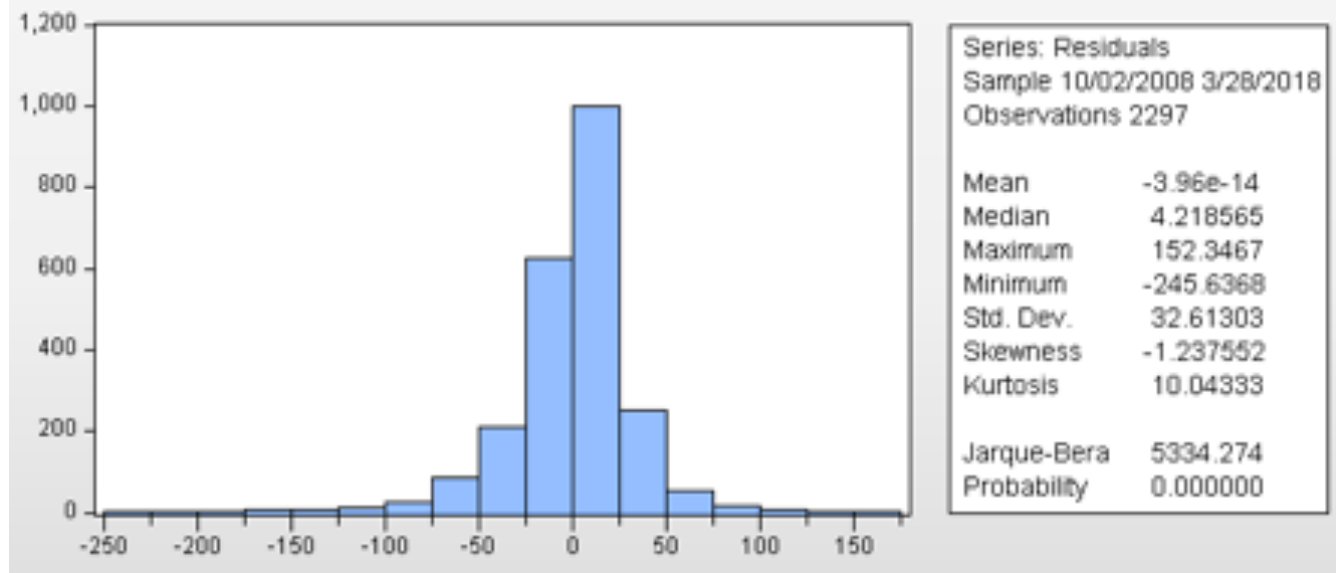

Tabla 2: Prueba de heterocedasticidad

Heteroskedasticity Test ARCH

\begin{tabular}{llll}
\hline \hline F-statistic & 1449.710 & Prob. $F(2,2292)$ & 0.0000 \\
Obs*R-squared & 1281.763 & Prob. Chi-Square(2) & 0.0000 \\
\hline \hline
\end{tabular}

Test Equation:

Dependent Variable: RESID"2

Method: Least Squares

Date: 12/08/18 Time: 10:14

Sample (adjusted): 10/06/2008 3/28/2018

Included observations: 2295 after adjustments

HAC standard errors \& covariance (Bartlett kernel, Newey-West fixed bandwidth $=9.0000$ )

\begin{tabular}{lrlll}
\hline \hline \multicolumn{1}{c}{ Variable } & Coefficient & Std. Error & t-Statistic & Prob. \\
\hline \hline C & 231.9947 & 45.09318 & 5.144784 & 0.0000 \\
RESID $2(-1)$ & 0.615676 & 0.108299 & 5.684979 & 0.0000 \\
RESID'2(-2) & 0.166690 & 0.087302 & 1.909345 & 0.0563 \\
\hline \hline R-squared & 0.558502 & Mean dependent var & 1063.824 \\
Adjusted R-squared & 0.558117 & S.D. dependent var & 3199.115 \\
S.E. of regression & 2126.588 & Akaike info criterion & 18.16373 \\
Sum squared resid & $1.04 E+10$ & Schwarz criterion & 18.17123 \\
Log likelihood & -20839.88 & Hannan-Quinn criter. & 18.16647 \\
F-statistic & 1449.710 & Durbin-Watson stat & 2.060657 \\
Prob(F-statistic) & 0.000000 & & & \\
\hline \hline
\end{tabular}


Figura 7: Pruebas de autocorrelación de los residuos

Correlogram of Residuals

\begin{tabular}{|c|c|c|c|c|c|c|}
\hline \multicolumn{7}{|c|}{$\begin{array}{l}\text { Date: } 12 \text { oblib Time: } 10: 15 \\
\text { Sample: } 1001 / 20083 / 28 / 2018 \\
\text { Inclused cbservations: } 2297\end{array}$} \\
\hline Autocorrelation & Partial Corresation & & $A C$ & PAC & Q-stat & Prob \\
\hline & & 1 & 0.853 & 0.853 & 1671.6 & 0,000 \\
\hline & E & 2 & 0.771 & 0.163 & 3040.4 & 0.000 \\
\hline & E & 3 & 0.718 & 0.109 & 4227.6 & 0.000 \\
\hline & E & 4 & 0.687 & 0.108 & 5313.4 & 0.000 \\
\hline & 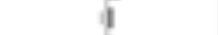 & 5 & 0.652 & 0.036 & 62921 & 0.000 \\
\hline & I & 6 & 0.622 & 0.040 & 7184.7 & 0.000 \\
\hline & i & 7 & 0.598 & 0.040 & 8010.2 & 0.000 \\
\hline & d & है & 0.572 & 0.010 & 8764.6 & 0.000 \\
\hline & 4 & 9 & 0.553 & 0.037 & 9471.0 & 0.000 \\
\hline 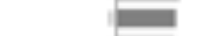 & 1 & 10 & 0.524 & -0.021 & 10106. & 0.000 \\
\hline $\bar{c}$ & i & 11 & 0.494 & -0.020 & 10668. & 0.000 \\
\hline & d & 12 & 0.469 & 0.003 & 11175 & 0.000 \\
\hline a & i & 13 & 0.445 & -0.004 & 11634. & 0.000 \\
\hline E & 1) & 14 & 0,430 & 0.022 & 12061. & 0.000 \\
\hline ב & 4 & 15 & 0.414 & 0.014 & 12458. & 0.000 \\
\hline 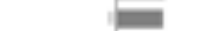 & i & 16 & 0.393 & -0.016 & 12816 . & 0.000 \\
\hline = & i & 17 & 0.382 & 0.030 & 13154. & 0.000 \\
\hline a & y & 18 & 0.375 & 0.029 & 13479. & 0.000 \\
\hline & i & 19 & 0.359 & -0.015 & 13778 . & 0.000 \\
\hline 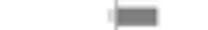 & 1 & 20 & 0.351 & 0.031 & 14062 & 0.000 \\
\hline = & 1 & 21 & 0.397 & -0.007 & 14327. & 0.000 \\
\hline 0 & i & 22 & 0.318 & $=0.027$ & 14562. & 0.000 \\
\hline ] & 1 & 23 & 0.303 & -0.002 & 14775 . & 0.000 \\
\hline ] & d) & 24 & 0.293 & 0.008 & 14975. & 0.000 \\
\hline E & 4 & 25 & 0.287 & 0.019 & 15166. & 0.000 \\
\hline E & d & 26 & 0.282 & 0.017 & 15351. & 0.000 \\
\hline = & 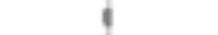 & 27 & 0.270 & -0.016 & 15522. & 0.000 \\
\hline 0 & $i$ & 28 & 0.252 & -0.028 & 15670 & 0.000 \\
\hline - & 1 & 29 & 0.244 & 0.015 & 15809. & 0.000 \\
\hline 口 & 1 & 30 & 0.233 & -0.010 & 15936. & 0.000 \\
\hline 물 & i & 31 & 0.216 & -0.024 & 16045 . & 0.000 \\
\hline D & 1 & 32 & 0.210 & 0.022 & 16147. & 0,000 \\
\hline e & 4 & 33 & 0.199 & -0.014 & 16240 & 0.000 \\
\hline 믈 & i & 34 & 0.186 & -0.015 & 16320 & 0.000 \\
\hline E & $i$ & 35 & 0.174 & -0.007 & 16391. & 0.000 \\
\hline E & $y$ & 36 & 0.173 & 0.029 & 16461. & 0.000 \\
\hline E & 1 & 37 & 0.169 & 0.012 & 16528. & 0.000 \\
\hline E & 1 & 38 & 0.175 & 0.045 & 16599. & 0.000 \\
\hline E & i & 39 & 0.169 & $=0.014$ & 16666. & 0.000 \\
\hline E & 1 & 40 & 0.159 & -0.015 & 16725 . & 0.000 \\
\hline
\end{tabular}




\begin{tabular}{|c|c|c|c|c|c|c|}
\hline \multicolumn{7}{|c|}{$\begin{array}{l}\text { Date: } 12 / 08 / 18 \text { Time: } 10: 16 \\
\text { Sample: } 1001 / 20083 / 28 / 2018 \\
\text { lincluded observations: } 2297\end{array}$} \\
\hline Ansocorretation & Partia Corretation & & $A C$ & PAC & Q-Stat & Prob \\
\hline & & 1 & 0.739 & 0.739 & 1255.5 & 0.000 \\
\hline & 㗐 & 2 & 0.622 & 0.167 & 2144.5 & 0.000 \\
\hline & 间 & 3 & 0.596 & 0.182 & 2935.6 & 0.000 \\
\hline & e & 4 & 0.578 & 0.157 & 37062 & 0.000 \\
\hline & 1 & 5 & 0.540 & 0.046 & 4378.8 & 0.000 \\
\hline 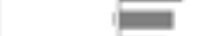 & i & 6 & 0.466 & -0.055 & 4878.3 & 0.000 \\
\hline 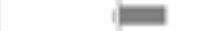 & E & 7 & 0.390 & -0.079 & 52288.6 & 0.000 \\
\hline 0 & i & 8 & 0.340 & -0.044 & 5495.5 & 0.000 \\
\hline 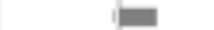 & i) & 9 & 0.318 & 0.013 & 5729.5 & 0.000 \\
\hline$=$ & i & 10 & 0.273 & .0 .032 & 5901.5 & 0.000 \\
\hline 0 & 1 & 11 & 0.249 & 0.042 & 6044.5 & 0.000 \\
\hline 口 & if & 12 & 0.217 & 0.005 & 6153.0 & 0.000 \\
\hline (1) & 1 & 13 & 0.171 & -0.042 & 6220.9 & 0.000 \\
\hline e & 1 & 14 & 0.138 & -0.025 & 6264.8 & 0.000 \\
\hline (1) & i) & 15 & 0.124 & 0,007 & 63002 & 0.000 \\
\hline in & i & 16 & $0.10 \mathrm{~s}$ & 0.001 & 6327.3 & 0.000 \\
\hline in & i) & 17 & 0.097 & 0.022 & 63492 & 0.000 \\
\hline in & 1 & 18 & 0.083 & 0.013 & 63650 & 0.000 \\
\hline 1 & i) & 19 & 0.069 & 0,008 & 63760 & 0.000 \\
\hline in & i) & 20 & 0.069 & 0.021 & 63872 & 0.000 \\
\hline in & 1 & 21 & 0.066 & 0.051 & 6404.4 & 0.000 \\
\hline 1) & il & 22 & 0.055 & -0.067 & 6411.4 & 0.000 \\
\hline 1 & 1 & 23 & 0.043 & $-0,007$ & 64157 & 0.000 \\
\hline it & i) & 24 & 0.043 & 0,002 & 6420.1 & 0.000 \\
\hline in & 11 & 25 & 0.055 & 0.026 & 6427.1 & 0.000 \\
\hline i1 & il & 26 & 0.070 & 0.044 & 6438.5 & 0.000 \\
\hline 1 & 1 & 27 & 0.039 & -0.058 & 6441.9 & 0.000 \\
\hline i) & 1 & 28 & 0.014 & .0036 & 6442.4 & 0.000 \\
\hline 1 & 1) & 29 & 0.023 & 0.016 & 6443.5 & 0.000 \\
\hline I & 1 & 30 & 0.028 & $=0.012$ & 6445.3 & 0.000 \\
\hline i) & i & 31 & 0.013 & -0.018 & 6445.7 & 0.000 \\
\hline 1) & 1) & 32 & 0.011 & 0.021 & 64450 & 0.000 \\
\hline 4 & 1 & 33 & $-0,000$ & -0.014 & 64450 & 0.000 \\
\hline i & i & 34 & .0009 & .0 .004 & 64462 & 0.000 \\
\hline 4 & i & 35 & 0.016 & 0.015 & 6445.8 & 0.000 \\
\hline 4 & 1) & 36 & -0.018 & 0,000 & 6447.5 & 0.000 \\
\hline i & i & 37 & $-0,023$ & $-0,008$ & 64487 & 0,000 \\
\hline i & il & 38 & -0.009 & 0.040 & 64489 & 0.000 \\
\hline 4 & i & 39 & 0.021 & -0.016 & 6450.0 & 0.000 \\
\hline 1 & i) & 40 & -0.027 & 0.004 & 6451.7 & 0.000 \\
\hline
\end{tabular}




\title{
Anexo 4. Modelo GARCH del margen total
}

\author{
$\operatorname{GARCH}(1,1)$
}

$\operatorname{Margen}_{\mathrm{t}}=\beta_{0}+\beta_{1} \log (\text { cupo })_{(\mathrm{t}-1)}+\beta_{2} \log (\operatorname{adjudicado})_{\mathrm{t}}+\beta_{3}$ utilización del cupo $_{(\mathrm{t}-1)}+\beta_{4} \%$ monto simultáneas $\mathrm{R} 2_{\mathrm{t}}+\varepsilon_{\mathrm{t}}$

Tabla 3

Dependent Variable: MARGEN

Method: ML ARCH - Normal distribution (BFGS / Marquardt steps)

Date: 1210818 Time: 10:19

Sample (adjusted): $10 / 02 / 2008$ 3/28/2018

Included observations: 2297 after adjustments

Comvergence achieved after 51 iterations

Coefficient covariance computed using outer product of gradients

Presample variance: backcast (parameter $=0.7$ )

$\mathrm{GARCH}=\mathrm{C}(6)+\mathrm{C}(7)^{*} \mathrm{RESID}(-1)^{n} 2+\mathrm{C}(8)^{*} \mathrm{GARCH}(-1)$

\begin{tabular}{crrrr}
\hline \hline Variable & Coefficient & Std. Error & z-Statistic & Prob. \\
\hline \hline C & -286.4168 & 6.999208 & -40.92131 & 0.0000 \\
LOG(CUPO(-1)) & 6.535515 & 0.745700 & 8.764268 & 0.0000 \\
LOG(ADUUDICADO) & 6.857774 & 0.469035 & 14.62102 & 0.0000 \\
UTILIZACION_CUPO(-1) & 11.66089 & 1.320948 & 8.827666 & 0.0000 \\
MONTO_R2 & 63.15194 & 1.161290 & 54.38085 & 0.0000 \\
\hline \hline & Variance Equation & & \\
\hline \hline C & 53.94681 & 2.452214 & 21.99922 & 0.0000 \\
RESID(-1) 2 & 0.811189 & 0.040303 & 20.12738 & 0.0000 \\
GARCH(-1) & 0.275104 & 0.019248 & 14.29238 & 0.0000 \\
\hline \hline R-squared & 0.148814 & Mean dependent var & -25.30370 \\
Adjusted R-squared & 0.147329 & S.D. dependent var & 37.83373 \\
S.E. of regression & 34.93573 & Akaike info criterion & 8.839464 \\
Sum squared resid & 2797399. & Schwarz criterion & 8.859453 \\
Log likelihood & -10144.12 & Hannan-Quinn criter. & 8.846752 \\
Durbin-Watson stat & 0.262372 & & & \\
\hline \hline
\end{tabular}


Figura 8: Prueba de normalidad

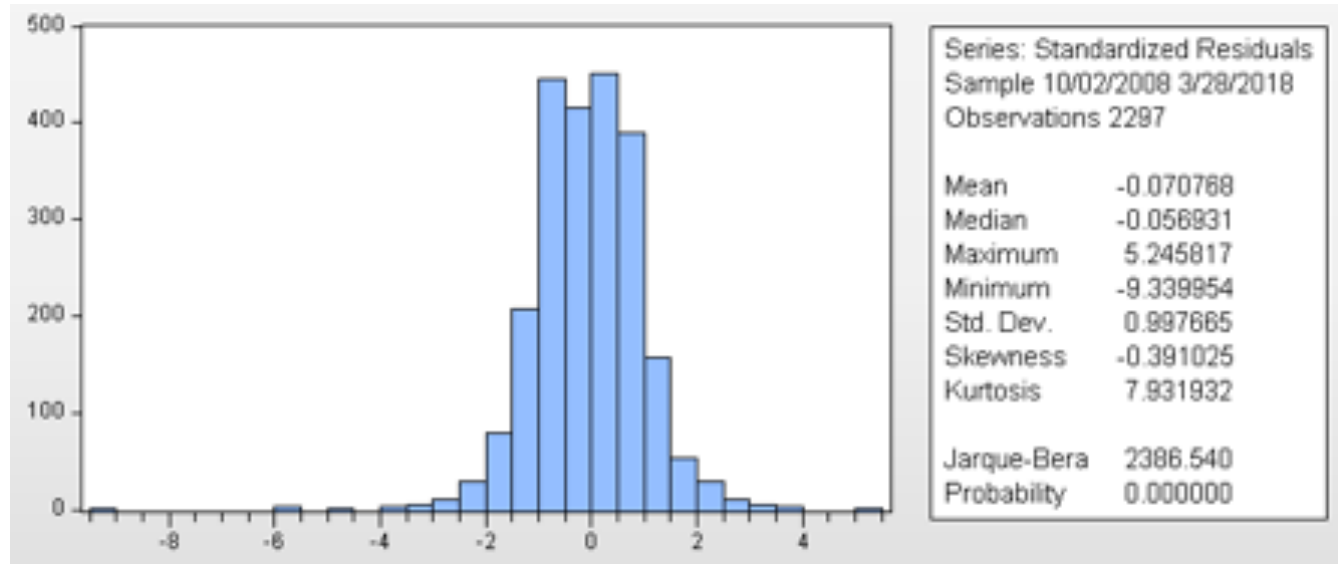

Tabla 4: Prueba de heterocedasticidad

Heteroskedasticity Test: ARCH

\begin{tabular}{llll}
\hline \hline F-statistic & 0.534038 & Prob. $F(2,2292)$ & 0.5863 \\
Obs*R-squared & 1.068975 & Prob. Chi-Square(2) & 0.5860 \\
\hline \hline
\end{tabular}

Test Equation:

Dependent Variable: WGT_RESID²

Method: Least Squares

Date: $12 / 08 / 18$ Time: 10:23

Sample (adjusted): $10 / 06 / 2008$ 3/28/2018

Included observations: 2295 after adjustments

\begin{tabular}{lrrrr}
\hline \hline \multicolumn{1}{c}{ Variable } & Coefficient & Std. Error & t-Statistic & Prob. \\
\hline \hline \multicolumn{1}{c}{ C } & 1.017249 & 0.062595 & 16.25140 & 0.0000 \\
WGT_RESID $2(-1)$ & 0.004549 & 0.020883 & 0.217814 & 0.8276 \\
WGT_RESID $2(-2)$ & -0.021155 & 0.020922 & -1.011168 & 0.3120 \\
\hline \hline R-squared & 0.000466 & Mean dependent var & 1.000722 \\
Adjusted R-squared & -0.000406 & S.D. dependent var & 2.645673 \\
S.E. of regression & 2.646210 & Akaike info criterion & 4.785441 \\
Sum squared resid & 16049.57 & Schwarz criterion & 4.792942 \\
Log likelihood & -5488.293 & Hannan-Quinn criter. & 4.788176 \\
F-statistic & 0.534038 & Durbin-Watson stat & 2.000813 \\
Prob(F-statistic) & 0.586306 & & & \\
\hline \hline
\end{tabular}


Figura 9: Pruebas de autocorrelación de los residuos

Conelogram of Standardoed Residuals

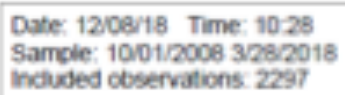

\begin{tabular}{|c|c|c|c|c|c|c|}
\hline Aunoconetation & Partal Contetion & & $A C$ & PAC & Q-stat & Proes \\
\hline 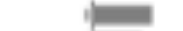 & 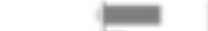 & 1 & 0.548 & 0.548 & 68958 & 0.000 \\
\hline E & ․ㅡ & 2 & 0.456 & 0223 & 11678 & 0.000 \\
\hline$\equiv$ & $=$ & 3 & 0.424 & 0.163 & 1582.1 & 0.000 \\
\hline 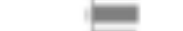 & e & 4 & 0.406 & 0.126 & 19613 & 0.000 \\
\hline 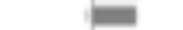 & 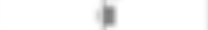 & 5 & 0.378 & 0.000 & 22912 & 0.000 \\
\hline E & 5 & 6 & 0397 & 0062 & 25053 & 0.000 \\
\hline E & 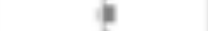 & 7 & 0.363 & 0.087 & 28898 & 0.000 \\
\hline = & 1 & 8 & 0.345 & 0.047 & 3163.8 & 0.000 \\
\hline$=$ & 1 & 9 & 0333 & 0044 & 3420.1 & 0.000 \\
\hline (1) & 4 & 10 & 0.308 & 0.013 & 3639.5 & 0.000 \\
\hline = & 4 & 11 & 0.284 & 0.016 & 38996 & 0.000 \\
\hline - & a & 12 & 0.282 & 0015 & 40233 & 0.000 \\
\hline a & 4 & 13 & 0.272 & 0.016 & 4194.7 & 0.000 \\
\hline = & 4 & 14 & 0.268 & 0.022 & 43609 & 0.000 \\
\hline = & 1 & 15 & 0.282 & 0.052 & 4544.7 & 0.000 \\
\hline e & i & 16 & 0.252 & -0.011 & 46912 & 0.000 \\
\hline = & ब) & 17 & 0.253 & 0.025 & 4839.6 & 0.000 \\
\hline - & 4 & 18 & 0.252 & 0.022 & 4986.1 & 0.000 \\
\hline - & 1 & 19 & 0.256 & 0.031 & 5136.6 & 0.000 \\
\hline - & $i$ & 20 & 0.265 & 0.047 & 53000 & 0.000 \\
\hline - & 1 & 21 & 0.263 & 0.030 & 5460.8 & 0.000 \\
\hline = & 4 & 22 & 0.254 & 0.011 & 5610.4 & 0.000 \\
\hline - & a & 23 & 0.245 & 0007 & 5749.3 & 0.000 \\
\hline = & a & 24 & 0.240 & 0,008 & 5883.4 & 0.000 \\
\hline - & a & 25 & 0.238 & 0,014 & 6015.1 & 0.000 \\
\hline [ & i & 25 & 0.224 & $-0,005$ & 61322 & 0.000 \\
\hline - & a & 27 & 0.233 & 0,023 & 62583 & 0.000 \\
\hline E & i & 28 & 0.194 & $-0,046$ & 63462 & 0.000 \\
\hline e & 4 & 29 & 0.215 & 0031 & E.454.1 & 0.000 \\
\hline E & i & 30 & 0.203 & .0005 & 66603 & 0.000 \\
\hline E & a & 31 & 0.202 & 0011 & 66450 & 0.000 \\
\hline e & a & 12 & 0.208 & 0.023 & 6745.5 & 0.000 \\
\hline - & i & 33 & 0.183 & -0.022 & 68233 & 0.000 \\
\hline E & 9 & 34 & 0.185 & 0,005 & 69030 & 0.000 \\
\hline E & i & 35 & 0.17 & $-0,002$ & 69762 & 0.000 \\
\hline E & d & 36 & 0.177 & 0.004 & 7049.1 & 0.000 \\
\hline a & i & 37 & $0.16 a$ & .0002 & 7114.8 & 0.000 \\
\hline E & 1 & 38 & 0.184 & 0.031 & 71938 & 0.000 \\
\hline E & 1 & 39 & 0.182 & 0.011 & 72713 & 0.000 \\
\hline E & a & 40 & 0.186 & 0020 & 7352.7 & 0.000 \\
\hline
\end{tabular}


Conetogram of Standardaed Residasts Squared

Date: 120818 Tme: $10: 30$

Samcle: $1001 / 200832827018$

indubed coservacns 229 ?

\begin{tabular}{|c|c|c|c|c|c|c|}
\hline Ausconetbon & Partial Certesation & & $A C$ & PAC & Q-52x & Prob" \\
\hline 4 & i) & 1 & 0.005 & $0 \cos$ & 0,0469 & 0.829 \\
\hline$i$ & i & 2 & 0.021 & .0021 & 1.0571 & 0.507 \\
\hline$i$ & $i$ & 3 & 0.019 & .0019 & 19185 & 0.569 \\
\hline 1 & 1 & 4 & 0.051 & 0001 & 78757 & 0.086 \\
\hline 4 & 1 & 5 & 0.007 & 0.006 & 8.0031 & 0.156 \\
\hline i & i & 6. & 0.007 & -0.005 & 8. 1252 & 0.229 \\
\hline i & 1 & 7. & -0.001 & 0.002 & 8. 1262 & 0.322 \\
\hline 4 & i & 8 & 0.014 & -0.016 & 8.5628 & 0.381 \\
\hline i & $i$ & 9. & 0.007 & 0.008 & 8.6752 & 0.468 \\
\hline 4 & i & 10. & 0.006 & -0.005 & 8.7490 & OSE6 \\
\hline 4 & i & 11 & 0.000 & $-0,009$ & 8.9117 & 0630 \\
\hline 1 & 1 & 12 & 0.042 & 0.043 & 12968 & 0.371 \\
\hline 4 & 1 & 13 & 0,000 & 0,000 & 12569 & 0.450 \\
\hline 4 & i & 14 & 0.015 & 0.013 & 13458 & 0.491 \\
\hline$i$ & 1 & 15 & 0.006 & 0.011 & 13615 & 0865 \\
\hline 4 & 1 & 16 & 0.019 & 0.013 & 14.415 & 0.568 \\
\hline$i$ & i & 17 & 0.010 & .0012 & 14600 & 0620 \\
\hline$i$ & $i$ & 18 & 0.013 & 0.011 & 15070 & 0.657 \\
\hline 4 & 1 & 19 & 0.004 & 0003 & 15.106 & 0716 \\
\hline 4 & 1 & 20 & 0.017 & 0.016 & 15.815 & 0.728 \\
\hline 1 & 1 & 21 & 0.025 & 0.005 & 17.273 & 0694 \\
\hline 4 & i & 22 & -0.005 & $-0,003$ & 17395 & 0.745 \\
\hline 4 & i & 23. & 0.014 & 0.012 & 17.779 & 0.769 \\
\hline$i$ & $i$ & 24. & 0.007 & -0009 & 17.886 & 0808 \\
\hline 4 & i & 25 & 0,000 & $-0,002$ & 17.804 & 0.847 \\
\hline 4 & 1 & 26 & 0.018 & 0.019 & 18.681 & 0.850 \\
\hline 1 & 1 & 27 & 0,001 & 0002 & 18683 & 0881 \\
\hline 4 & i & 28. & $-0,020$ & -0.019 & 19.581 & 0.879 \\
\hline 4 & i & 29 & 0.020 & 0.017 & 20511 & 0.876 \\
\hline$t$ & i & 30 . & 0,009 & 0010 & 20690 & 0.897 \\
\hline 4 & i & 31 & 0.001 & 0.003 & 20.694 & 0920 \\
\hline 4 & 1 & 32 & 0.003 & 0,003 & 20719 & 0900 \\
\hline 4 & 1 & 33 & 0,008 & 0,003 & 20862 & 0960 \\
\hline 4 & i & 34 & 0.007 & 0,005 & 20991 & 0961 \\
\hline 4 & 1 & 35 & 0,023 & 0005 & 22.292 & 0964 \\
\hline 4 & if & 36 & 0.018 & 0017 & 23016 & 0964 \\
\hline 4 & 1 & 37 & 0.018 & 0.020 & 23.700 & 0905 \\
\hline 1 & 1 & 38 & 0,020 & 0,02 & 24755 & 0952 \\
\hline 4 & $i$ & 39. & -0.014 & -0.017 & 25.238 & 0.957 \\
\hline 4 & 1 & 40 & 0.015 & 0.014 & 25.743 & 0961 \\
\hline
\end{tabular}




\title{
Anexo 5. Modelo margen de la serie del rango R2
}

\author{
Margen_R $2_{\mathrm{t}}=\beta_{0}+\beta_{1} \log (\text { cupo })_{(\mathrm{t}-1)}+\beta_{2} \log (\text { adjudicado })_{\mathrm{t}}+\beta_{3}$ \\ utilización del cupo $\operatorname{t(t-1)}+\beta_{4} \%$ monto simultáneas $\mathrm{R} 2_{\mathrm{t}}+\varepsilon_{\mathrm{t}}$
}

Tabla 5

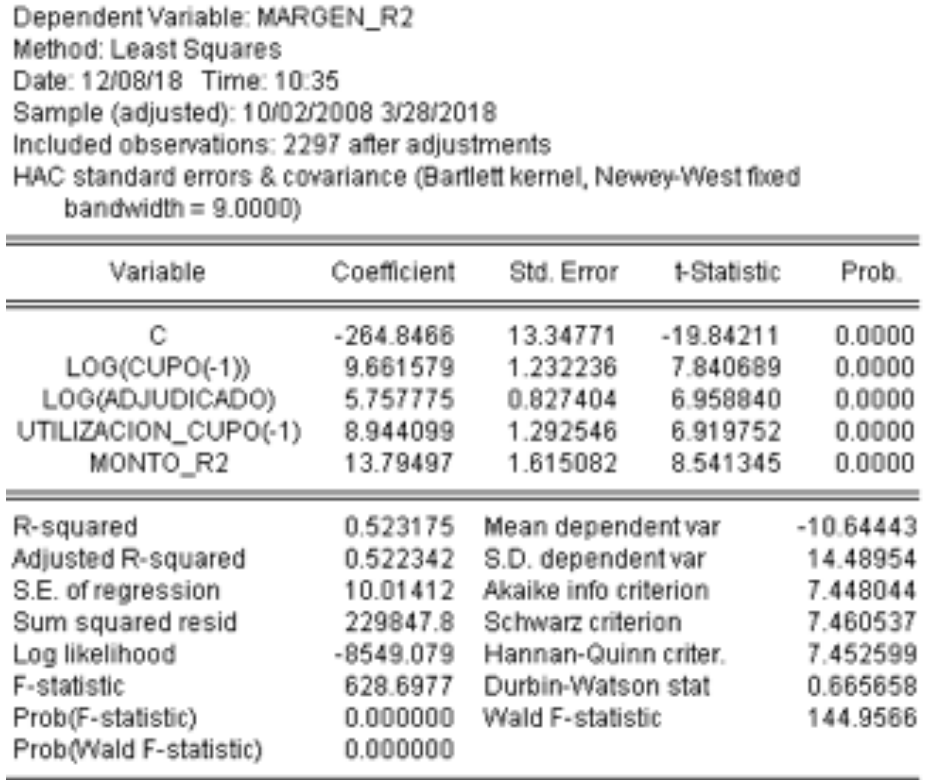

Figura 10: Pruebas estadísticas del modelo margen de la serie del rango R2

Prueba de normalidad

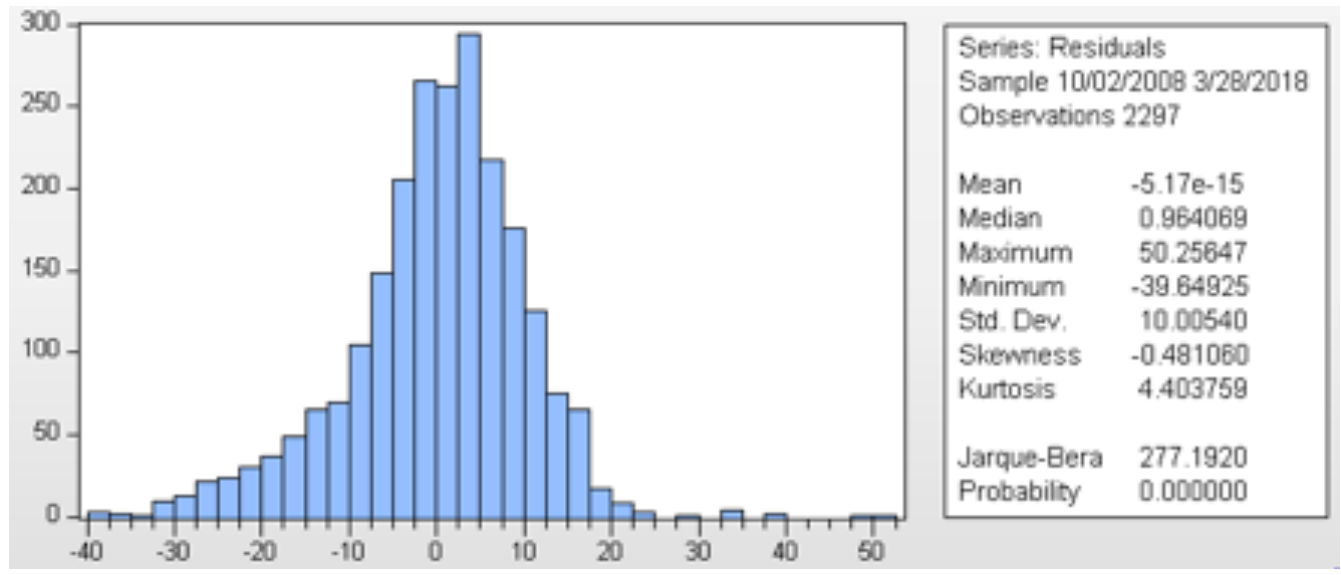


Tabla 6: Prueba de heterocedasticidad

Heteroskedasticity Test. ARCH

\begin{tabular}{llll}
\hline \hline F-statistic & 302.7491 & Prob. $F(2,2292)$ & 0.0000 \\
Obs*R-squared & 479.5925 & Prob. Chi-Square(2) & 0.0000 \\
\hline \hline
\end{tabular}

Test Equation:

Dependent Variable: RESID'2

Method: Least Squares

Date: $12 / 08 / 18$ Time: 10:38

Sample (adjusted): 10/06/2008 3/28/2018

Included observations: 2295 after adjustments

HAC standard errors \& covariance (Bartlett kemel, Newey-West fixed bandwidth $=9.0000$ )

\begin{tabular}{lrlll}
\hline \hline \multicolumn{1}{c}{ Variable } & Coefficient & Std. Error & t-Statistic & Prob. \\
\hline \hline \multicolumn{1}{c}{ C } & 46.46097 & 4.709402 & 9.865577 & 0.0000 \\
RESID $2(-1)^{n}$ & 0.333563 & 0.043975 & 7.585377 & 0.0000 \\
RESID $2(-2)^{\prime}$ & 0.203243 & 0.051725 & 3.929294 & 0.0001 \\
\hline \hline R-squared & 0.208973 & Mean dependent var & 100.0881 \\
Adjusted R-squared & 0.208283 & S.D. dependent var & 184.7276 \\
S.E. of regression & 164.3678 & A.kaike info criterion & 13.04340 \\
Sum squared resid & 61922465 & Schwar criterion & 13.05090 \\
Log likelihood & -14964.30 & Hannan-Quinn criter. & 13.04613 \\
F-statistic & 302.7491 & Durbin-Watson stat & 2.022758 \\
Prob(F-statistic) & 0.000000 & & & \\
\hline \hline
\end{tabular}


Figura 11: Pruebas de autocorrelación de los residuos

Conelogram of Residuals

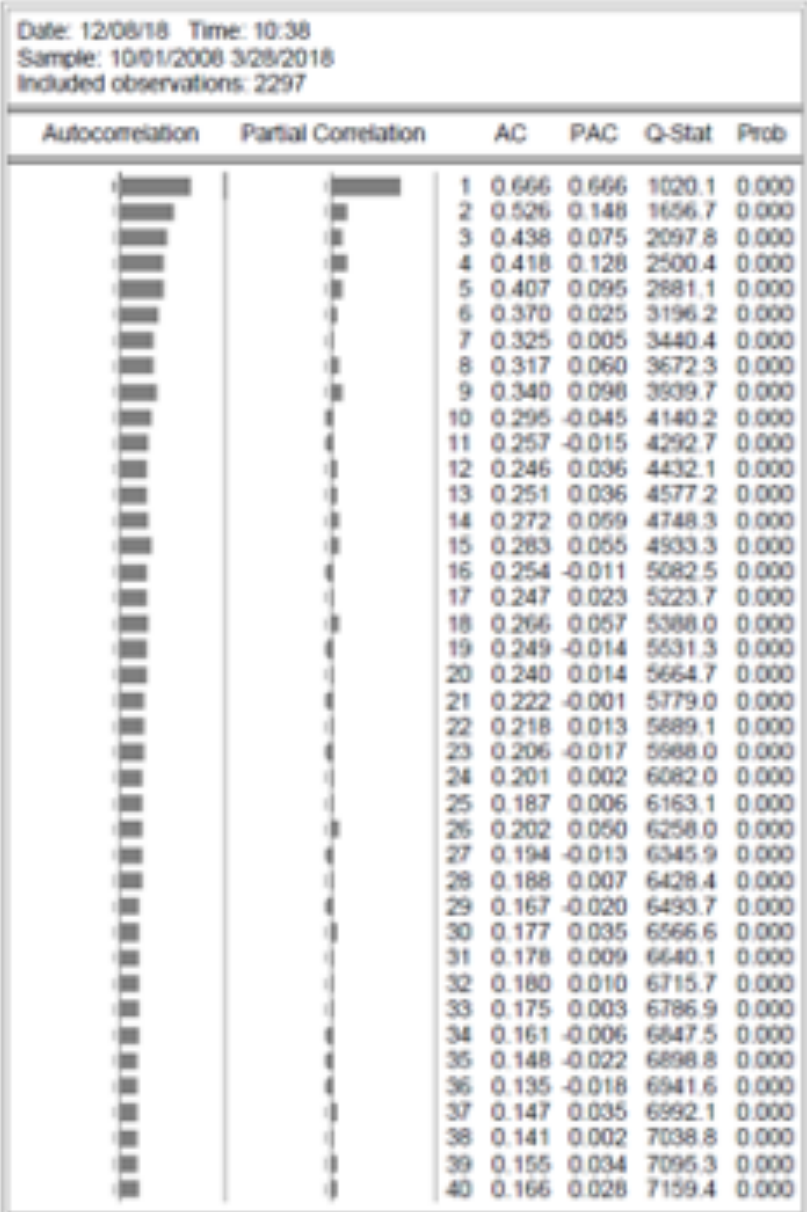




\begin{tabular}{|c|c|c|c|c|c|c|}
\hline Altocorretation & Panal Corretabon & & $A C$ & PAC & Q-stat & Prob \\
\hline 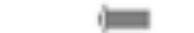 & $=$ & 1 & 0.418 & 0.418 & 401.72 & 0,000 \\
\hline$=$ & - & 2 & 0.362 & 0.200 & 67122 & 0000 \\
\hline 回 & I & 3 & 0.250 & 0055 & 81555 & 0000 \\
\hline E & 1 & 4 & 0.235 & 0.003 & 94231 & 0000 \\
\hline D & 1 & 5 & 0207 & 0.056 & 1040.8 & 0,000 \\
\hline 통 & j & 6 & 0.197 & 0.054 & 1130.7 & 0,000 \\
\hline 回 & i) & 7 & 0.210 & 0.077 & 123322 & 0000 \\
\hline E & 6 & 8 & 0200 & 0.102 & 1365.4 & 0000 \\
\hline (日) & 1 & 9 & 0.231 & 0.080 & 145a. 1 & 0000 \\
\hline 폴 & $i$ & 10 & 0.167 & -0.026 & 1552.9 & 0,000 \\
\hline E & 1 & 11 & 0.181 & 0.041 & 1628.6 & 0,000 \\
\hline E & i & 12 & 0.136 & 0.016 & 1671.2 & 0000 \\
\hline E & $i$ & 13 & 0.121 & -0.010 & 17052 & 0000 \\
\hline E & i & 14 & 0.123 & 0019 & 17400 & 0000 \\
\hline n & $i$ & 15 & 0.101 & 0.015 & 1763.9 & 0000 \\
\hline E & 1 & 16 & 0.141 & 0.049 & 1809.7 & 0,000 \\
\hline E & $i$ & 17 & 0.118 & .0 .000 & 1842.0 & 0000 \\
\hline E & i & 18 & 0.199 & 0.099 & 1606.9 & 0000 \\
\hline E & i & 19 & 0.105 & -0012 & 19123 & 0000 \\
\hline 㗐 & i & 20 & 0.125 & 0.002 & 1948.7 & 0000 \\
\hline E & i & 21 & 0.129 & 0.042 & 1987.6 & 0000 \\
\hline E & 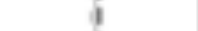 & $n$ & 0.147 & 0.045 & 20377 & 0000 \\
\hline E & i & 23 & 0.145 & 0.033 & 2066.7 & 0000 \\
\hline E & i & 24 & 0.130 & 0005 & 2126.2 & 0000 \\
\hline E & 1 & 25 & 0.150 & 0.036 & 2178.2 & 0,000 \\
\hline E & 1 & 26 & 0.157 & 0.043 & 2235.5 & 0000 \\
\hline E & j & 27 & 0.163 & 0.082 & $2207 / 4$ & 0000 \\
\hline E & g & 28 & 0.199 & 0,000 & 23425 & 0000 \\
\hline E & 4 & 29 & 0.144 & 0.012 & 2380.6 & 0000 \\
\hline E & d & 30 & 0.137 & 0.007 & 24341 & 0,000 \\
\hline E & 8 & 31 & 0.131 & 0.000 & 24742 & 0000 \\
\hline E & $i$ & 32 & 0.104 & 0.005 & 2499.5 & 0000 \\
\hline E & $i$ & 33 & 0.092 & -0.018 & 25192 & 0000 \\
\hline n & $i$ & 34 & 0.096 & .0 .007 & 2540.5 & 0000 \\
\hline 5 & i & 36 & 0.051 & -0.056 & 2546.6 & 0000 \\
\hline i & 1 & 36 & 0062 & $-0 \cos 2$ & 25529 & 0000 \\
\hline 1 & it & 37 & 0.066 & 0.014 & 25630 & 0000 \\
\hline in & 1 & 38 & 0.089 & 0.008 & 25817 & 0000 \\
\hline (1) & $i$ & 39 & 0,062 & 0.007 & 2597.6 & 0000 \\
\hline 5 & $i$ & 40 & 0.060 & 0.017 & 2606.1 & 0000 \\
\hline
\end{tabular}




\section{GARCH $(2,2)$}

\section{Margen_R $2_{\mathrm{t}}=\beta_{0}+\beta_{1} \log (\text { cupo })_{(\mathrm{t}-1)}+\beta_{2} \log (\text { adjudicado })_{\mathrm{t}}+\beta 3$ utilización del cupo (t-1) $+\beta_{4} \%$ monto simultáneas $\mathrm{R} 2_{\mathrm{t}}+\varepsilon_{\mathrm{t}}$}

\section{Tabla 7}

Dependent Variable: MARGEN_R2

Method: MLARCH - Normal distribution (BFGS / Marquardt steps)

Date: 1210848 Time: 10:43

Sample (adjusted): $10 / 02 / 2008$ 3/28/2018

Included observations: 2297 after adjustments

Corvergence achieved after 84 iterations

Coefficient covariance computed using outer product of gradients

Presample variance: backcast (parameter $=0.7$ )

$\mathrm{GARCH}=\mathrm{C}(6)+\mathrm{C}(7)^{*} \mathrm{RESID}(-1)^{a} 2+\mathrm{C}(8)^{*} \mathrm{RESID}(-2)^{\wedge} 2+\mathrm{C}(9)^{*} \mathrm{GARCH}(-1)$

$+\mathrm{C}(10)^{*} \mathrm{GARCH}(-2)$

\begin{tabular}{|c|c|c|c|c|}
\hline Variable & Coemicient & Std. Error & $z$-Statistic & Prob. \\
\hline $\mathrm{C}$ & -133.4932 & 4.926365 & -27.09772 & 0.0000 \\
\hline LOG(CUPO(-1)) & 3.125944 & 0.376251 & 8.308140 & 0.0000 \\
\hline LOG(ADUUDICADO) & 4.620255 & 0.238918 & 19.33824 & 0.0000 \\
\hline UTILIZACION_CUPO(-1) & 5.320022 & 0.602307 & 8.832746 & 0.0000 \\
\hline MONTO_R2 & 6.739514 & 0.318229 & 21.17816 & 0.0000 \\
\hline \multicolumn{5}{|c|}{ Variance Equation } \\
\hline $\mathrm{C}$ & 0.397989 & 0.073313 & 5.428641 & 0.0000 \\
\hline $\operatorname{RESID}(-1)^{n} 2$ & 0.769080 & 0.040672 & 18.90950 & 0.0000 \\
\hline $\operatorname{RESID}(-2)^{n} 2$ & -0.726294 & 0.038720 & -18.75739 & 0.0000 \\
\hline GARCH(-1) & 1.092159 & 0.028510 & 38.30735 & 0.0000 \\
\hline GARCH $(-2)$ & -0.133633 & 0.025600 & -5.220032 & 0.0000 \\
\hline R-squared & 0.311541 & \multicolumn{2}{|c|}{ Mean dependent var } & -10.64443 \\
\hline Adjusted R-squared & 0.310340 & \multicolumn{2}{|c|}{ S.D. dependent var } & 14.4895 \\
\hline S.E. of regression & 12.03295 & \multicolumn{2}{|c|}{ Akaike info criterion } & 7.008681 \\
\hline Sum squared resid & 331863.0 & \multicolumn{2}{|c|}{ Schwarz criterion } & 7.033668 \\
\hline Log likelihood & -8039.471 & \multicolumn{2}{|c|}{ Hannan-Quinn criter. } & 7.01779 \\
\hline Durbin-Watson stat & 0.436385 & & & \\
\hline
\end{tabular}


Figura 12: Prueba de normalidad

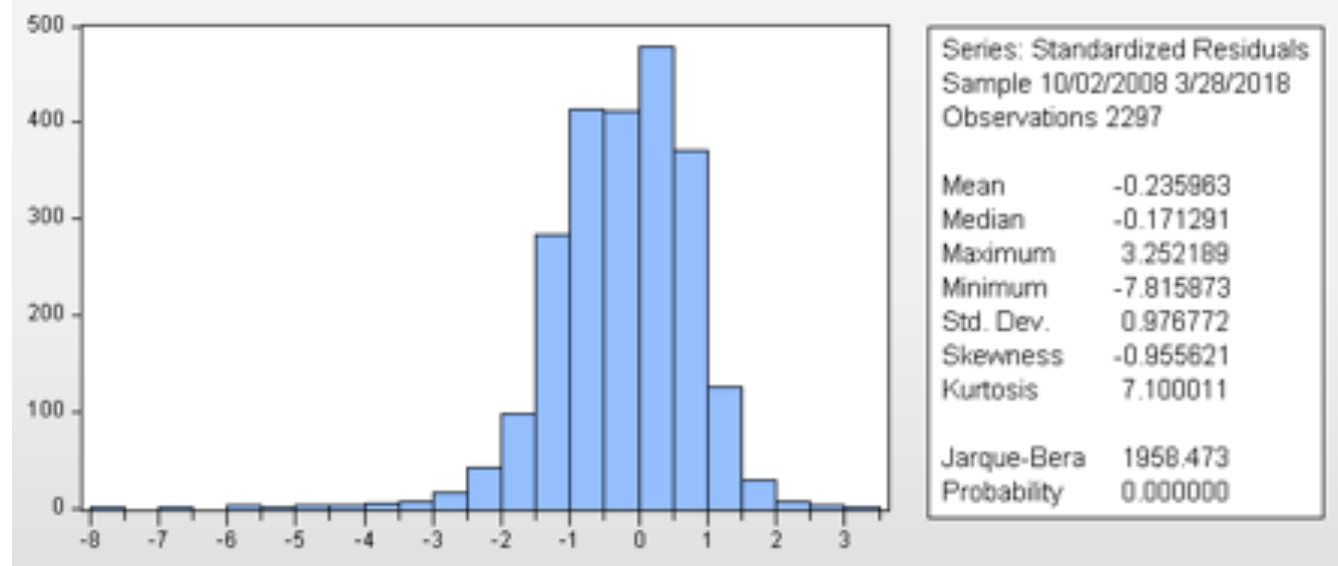

Tabla 8: Prueba de heterocedasticidad

Heteroskedasticity Test: $A R C H$

\begin{tabular}{llll}
\hline \hline F-statistic & 0.625294 & Prob. F(2,2292) & 0.5352 \\
Obs*R-squared & 1.251541 & Prob. Chi-Square(2) & 0.5348 \\
\hline \hline
\end{tabular}

Test Equation:

Dependent Variable: WGT_RESID²

Method: Least Squares

Date: $12 / 08 / 18$ Time: $10-48$

Sample (adjusted): $10 / 06 / 2008$ 3/28/2018

Included observations: 2295 afer adjustments

\begin{tabular}{lrlll}
\hline \hline \multicolumn{1}{c}{ Variable } & Coefficient & Std. Error & t-Statistic & Prob. \\
\hline \hline \multicolumn{1}{c}{ C } & 1.029653 & 0.061352 & 16.78277 & 0.0000 \\
WGT_RESID 2(-1) & 0.001985 & 0.020874 & 0.095092 & 0.9243 \\
WGT_RESID 2(-2) & -0.023367 & 0.020969 & -1.114339 & 0.2653 \\
\hline \hline R-squared & 0.000545 & Mean dependent var & 1.008201 \\
Adjusted R-squared & -0.000327 & S.D. dependent var & 2.569581 \\
S.E. of regression & 2.570001 & Akaike info criterion & 4.726996 \\
Sum squared resid & 15138.44 & Schwarz criterion & 4.734497 \\
Log likelihood & -5421.228 & Hannan-Quinn criter. & 4.729731 \\
F-statistic & 0.625294 & Durbin-Watson stat & 2.000314 \\
Prob(F-statistic) & 0.535196 & & & \\
\hline \hline
\end{tabular}


Figura 13: Pruebas de autocorrelación de los residuos Correlogram of Standardzed Residuals

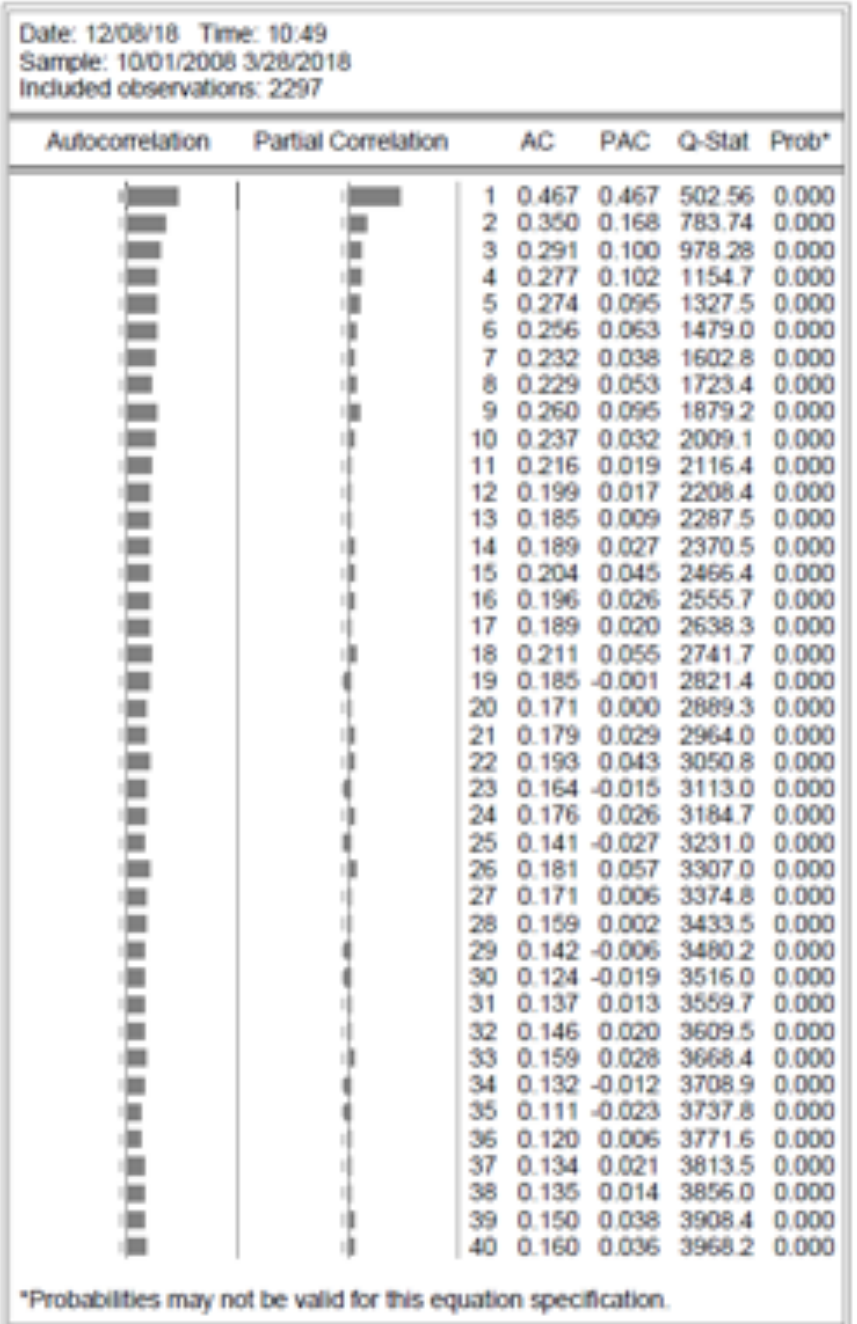




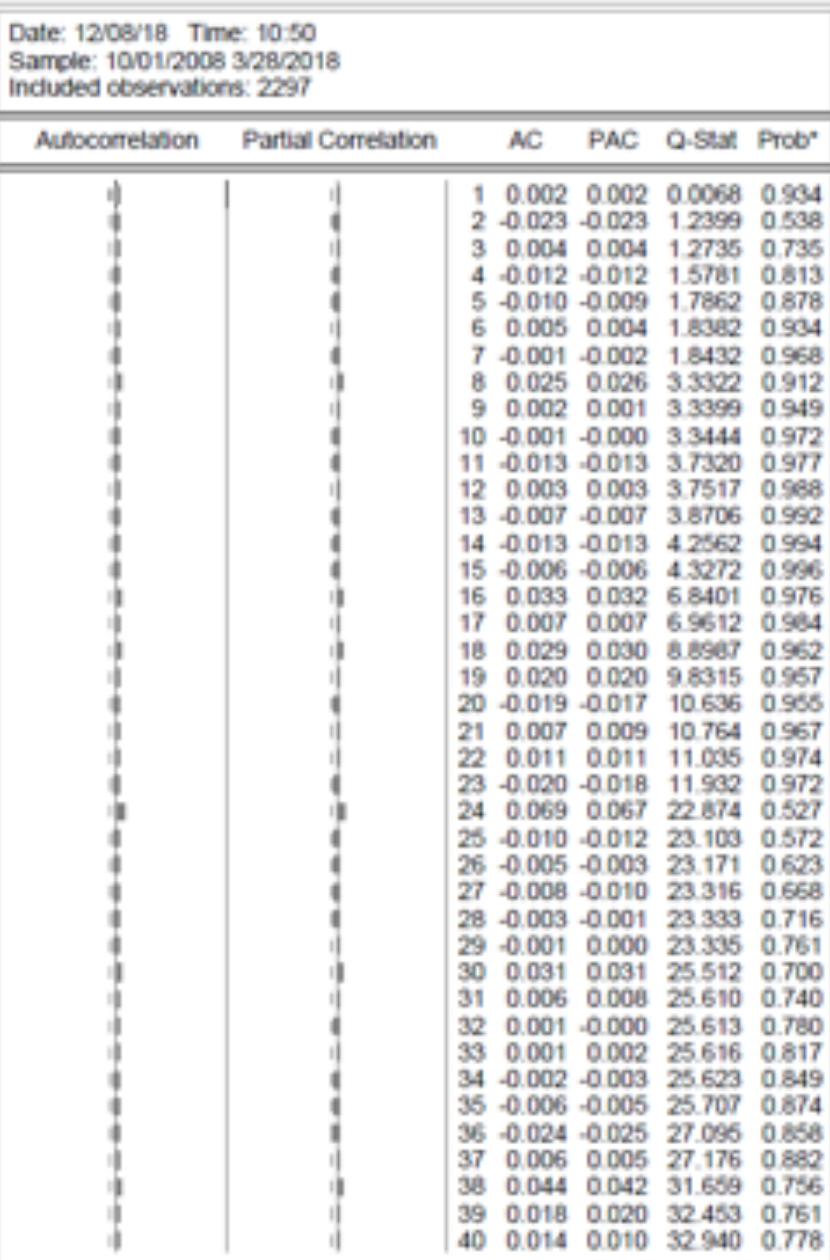

"Probabiltes may not be valid for this equason specification. 


\section{Anexo 6. Modelo margen R1}

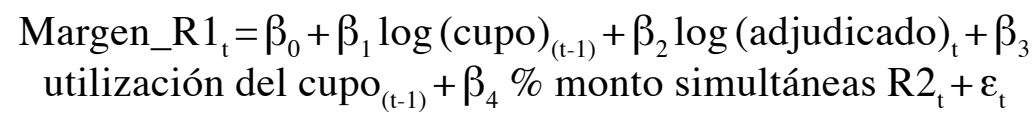

Tabla 9

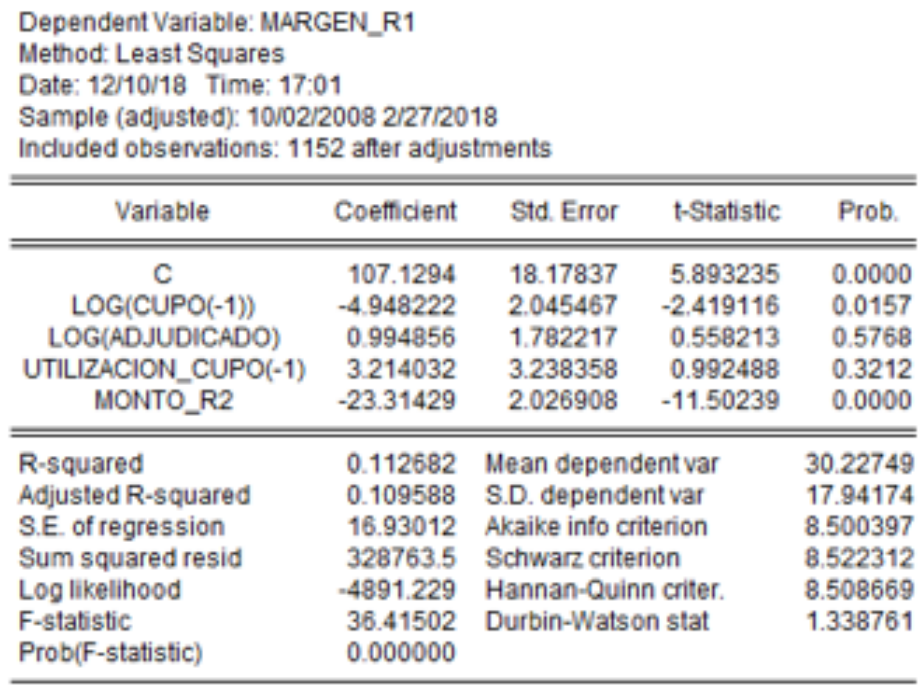

Figura 14: Prueba de normalidad

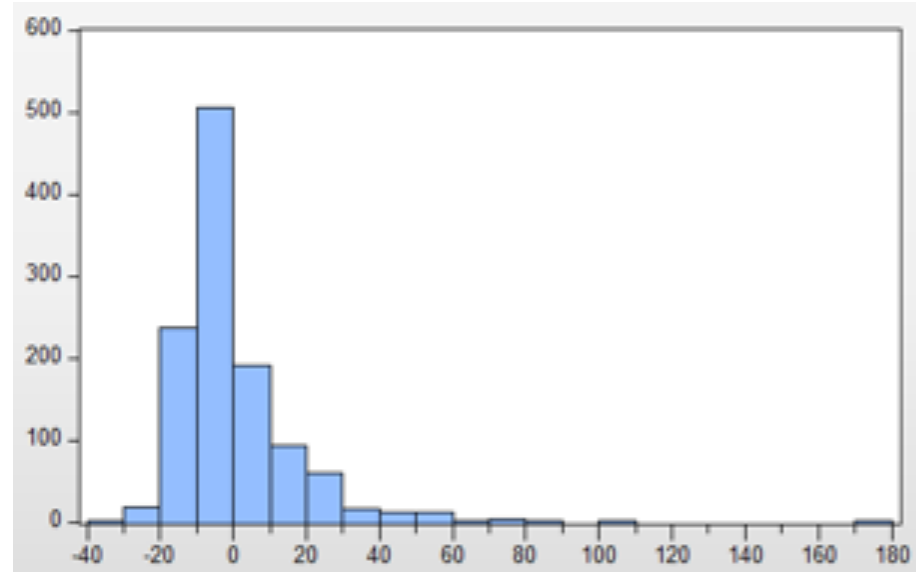

Series: Residuals

Sample 10102/2008 2/27/2018

Observations 1152

Mean

$-5.86 \mathrm{e}-14$

Median

$-4.598841$

Maximum

176.3032

Minimum

33.60935

Std. Dev.

16.90068

Skewness $\quad 3.415432$

Kurtosis $\quad 25.96774$

Jarque-Bera $\quad 27560.54$

Probability $\quad 0.000000$ 
Tabla 10: Prueba de heterocedasticidad

Heteroskedasticity Test ARCH

\begin{tabular}{llll}
\hline \hline F-statistic & 1.168255 & Prob. $F(2,1139)$ & 0.3113 \\
Obs"R-squared & 2.337869 & Prob. Chi-Square(2) & 0.3107 \\
\hline \hline
\end{tabular}

Test Equation:

Dependent Variable: RESID^2

Method: Least Squares

Date: $12 / 10 / 18$ Time: $17: 34$

Sample (adjusted): 10/08/2008 2/27/2018

Included observations: 1142 after adjustments

\begin{tabular}{lrlll}
\hline \hline \multicolumn{1}{c}{ Variable } & Coefficient & Std. Error & t-Statistic & Prob. \\
\hline \hline \multicolumn{1}{c}{ C } & 257.9771 & 43.54552 & 5.924309 & 0.0000 \\
RESID $2(-1)$ & 0.032319 & 0.030128 & 1.072725 & 0.2836 \\
RESID $^{\wedge}(-2)$ & 0.031660 & 0.030057 & 1.053324 & 0.2924 \\
\hline \hline R-squared & 0.002047 & Mean dependent var & 275.3976 \\
Adjusted R-squared & 0.000295 & S.D. dependent var & 1420.465 \\
S.E. of regression & 1420.256 & Akaike info criterion & 17.35768 \\
Sum squared resid & $2.30 E+09$ & Schwarz criterion & 17.37093 \\
Log likelihood & -9908.238 & Hannan-Quinn criter. & 17.36268 \\
F-statistic & 1.168255 & Durbin-Watson stat & 1.974659 \\
Prob(F-statistic) & 0.311281 & & & \\
\hline \hline
\end{tabular}


Figura 15: Pruebas de autocorrelación de los residuos

Correlogram of Residuals

Date: $12 / 10 / 18$ Time: $17: 34$

Sample: $10 / 01 / 2008$ 2/27/2018

Included observations: 1152

\begin{tabular}{|c|c|c|c|c|c|c|}
\hline Autocorrelation & Partial Correlation & & $A C$ & PAC & Q-Stat & Prob \\
\hline 10 & (口 & 1 & 0.304 & 0.304 & 106.61 & 0.000 \\
\hline$=$ & 间 & 2 & 0.243 & 0.166 & 175.05 & 0.000 \\
\hline 回 & 17 & 3 & 0.200 & 0.099 & 221.14 & 0.000 \\
\hline D & 回 & 4 & 0.253 & 0.162 & 295.40 & 0.000 \\
\hline 回 & i) & 5 & 0.159 & 0.018 & 324.63 & 0.000 \\
\hline 国 & if & 6 & 0.150 & 0.036 & 350.85 & 0.000 \\
\hline 回 & 11 & 7 & 0.170 & 0.072 & 384.39 & 0.000 \\
\hline E & 11 & 8 & 0.161 & 0.042 & 414.39 & 0.000 \\
\hline in & 10 & 9 & 0.108 & -0.007 & 427.92 & 0.000 \\
\hline in & if & 10 & 0.083 & -0.014 & 436.02 & 0.000 \\
\hline if & 11 & 11 & 0.111 & 0.032 & 450.46 & 0.000 \\
\hline 17 & if & 12 & 0.089 & 0.002 & 459.62 & 0.000 \\
\hline i. & 11 & 13 & 0.096 & 0.029 & 470.31 & 0.000 \\
\hline in & if & 14 & 0.086 & 0.016 & 478.92 & 0.000 \\
\hline 17 & if & 15 & 0.087 & 0.010 & 487.71 & 0.000 \\
\hline 1. & 11 & 16 & 0.094 & 0.032 & 498.05 & 0.000 \\
\hline$\sqrt{1}$ & 11 & 17 & 0.072 & 0.000 & 504.15 & 0.000 \\
\hline if & 11 & 18 & 0.099 & 0.041 & 515.64 & 0.000 \\
\hline 1$]$ & if & 19 & 0.093 & 0.022 & 525.74 & 0.000 \\
\hline 16 & if & 20 & 0.118 & 0.047 & 542.00 & 0.000 \\
\hline 1 & 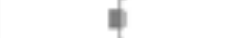 & 21 & 0.036 & -0.055 & 543.52 & 0.000 \\
\hline 11 & if & 22 & 0.068 & 0.009 & 548.99 & 0.000 \\
\hline 17 & if & 23 & 0.054 & -0.005 & 552.40 & 0.000 \\
\hline in & if & 24 & 0.078 & 0.020 & 559.50 & 0.000 \\
\hline 1 & if & 25 & 0.029 & $=0.024$ & 560.46 & 0.000 \\
\hline i) & d & 26 & 0.024 & -0.027 & 561.14 & 0.000 \\
\hline 11 & 11 & 27 & 0.049 & 0.018 & 563.97 & 0.000 \\
\hline 11 & 11 & 28 & 0.060 & 0.025 & 568.19 & 0.000 \\
\hline$\sqrt{1}$ & 11 & 29 & 0.056 & 0.025 & 571.94 & 0.000 \\
\hline 1 & if & 30 & 0.054 & 0.016 & 575.42 & 0.000 \\
\hline 1] & 11 & 31 & 0.075 & 0.026 & 582.10 & 0.000 \\
\hline 1 & if & 32 & 0.067 & 0.016 & 587.46 & 0.000 \\
\hline$\sqrt{1}$ & if & 33 & 0.062 & 0.009 & 591.98 & 0.000 \\
\hline 17 & 16 & 34 & 0.071 & 0.023 & 597.92 & 0.000 \\
\hline 11 & if & 35 & 0.063 & -0.003 & 602.62 & 0.000 \\
\hline 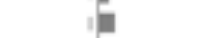 & 11 & 36 & 0.100 & 0.049 & 614.58 & 0.000 \\
\hline in & if & 37 & 0.083 & 0.017 & 622.84 & 0.000 \\
\hline II & 16 & 38 & 0.079 & 0.003 & 630.38 & 0.000 \\
\hline 11 & if & 39 & 0.065 & 0,000 & 635.36 & 0.000 \\
\hline in & if & 40 & 0.088 & 0.023 & 644.64 & 0.000 \\
\hline
\end{tabular}


Date: $12 / 10 / 18$ Time: $17: 35$

Sample: 1001//2008 2/27/2018

Included observations: 1152

\begin{tabular}{|c|c|c|c|c|c|c|}
\hline Autocorrelation & Partial Correlation & & $A C$ & PAC & Q-Stat & Prob \\
\hline i) & 11 & 1 & 0.040 & 0.040 & 1.8190 & 0.177 \\
\hline if & if & 2 & 0.048 & 0.046 & 4.4526 & 0.108 \\
\hline if & 11 & 3 & 0.067 & 0.064 & 9.6902 & 0.021 \\
\hline ii & 15 & 4 & 0.048 & 0.041 & 12.349 & 0.015 \\
\hline i) & if & 5 & 0.015 & 0.006 & 12.613 & 0.027 \\
\hline if & if & 6 & 0.012 & 0.003 & 12.771 & 0.047 \\
\hline if & 1 & 7 & 0.079 & 0.073 & 20.009 & 0.006 \\
\hline$\sqrt{5}$ & if & 8 & 0.022 & 0.014 & 20.591 & 0.008 \\
\hline 1 & if & 9 & -0.004 & $=0.014$ & 20.614 & 0.014 \\
\hline if & if & 10 & 0.001 & -0.010 & 20.615 & 0.024 \\
\hline i) & if & 11 & 0.009 & 0.001 & 20.701 & 0.037 \\
\hline i & if & 12 & -0.004 & -0.006 & 20.723 & 0.055 \\
\hline ij & if & 13 & -0.002 & -0.002 & 20.730 & 0.078 \\
\hline 5 & if & 14 & -0.002 & -0.007 & 20.733 & 0.109 \\
\hline 1 & i & 15 & -0.008 & -0.010 & 20.817 & 0.143 \\
\hline 10 & if & 16 & -0.001 & 0.002 & 20.819 & 0.186 \\
\hline i) & if & 17 & -0.007 & -0.004 & 20.871 & 0.232 \\
\hline i) & if & 18 & 0.021 & 0.023 & 21.407 & 0.259 \\
\hline i) & if & 19 & 0.022 & 0.023 & 21.976 & 0.285 \\
\hline if & if & 20 & 0.031 & 0.029 & 23.086 & 0.285 \\
\hline if & if & 21 & -0.008 & -0.013 & 23.160 & 0.336 \\
\hline if & if & 22 & -0.013 & -0.018 & 23.350 & 0.382 \\
\hline i) & if & 23 & -0.012 & -0.016 & 23.524 & 0.431 \\
\hline i) & if & 24 & 0.004 & 0.005 & 23.542 & 0.488 \\
\hline i & if & 25 & -0.008 & -0.009 & 23.626 & 0.541 \\
\hline 5 & i) & 26 & -0.015 & -0.017 & 23.891 & 0.582 \\
\hline 1 & i) & 27 & -0.009 & -0.012 & 23.994 & 0.631 \\
\hline if & if & 28 & 0.002 & 0.006 & 23.997 & 0.682 \\
\hline i) & if & 29 & -0.003 & 0.003 & 24.011 & 0.728 \\
\hline if & if & 30 & -0.012 & -0.007 & 24.190 & 0.763 \\
\hline i) & i) & 31 & -0.007 & -0.007 & 24.256 & 0.800 \\
\hline i & i) & 32 & -0.005 & -0.003 & 24.291 & 0.834 \\
\hline 1 & if & 33 & -0.014 & -0.008 & 24.516 & 0.857 \\
\hline 10 & if & 34 & -0.011 & -0.006 & 24.670 & 0.880 \\
\hline 1 & if & 35 & -0.001 & 0.001 & 24.672 & 0.903 \\
\hline i) & if & 36 & 0.016 & 0.018 & 24.988 & 0.916 \\
\hline i & if & 37 & -0.003 & -0.001 & 24.996 & 0.934 \\
\hline ij & if & 38 & -0.008 & $=0.010$ & 25.077 & 0.947 \\
\hline if & if & 39 & -0.005 & $=0.008$ & 25.111 & 0.958 \\
\hline i) & if & 40 & 0.004 & 0.006 & 25.131 & 0.968 \\
\hline
\end{tabular}

